\title{
Experimental and Theoretical Insights into the Electronic Properties of Anionic N-Heterocyclic Dicarbenes through the Rational Synthe- sis of Their Transition Metal Complexes
}

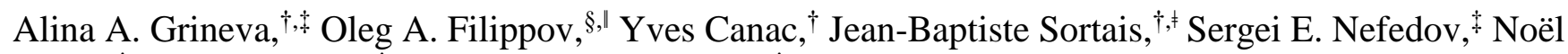 \\ Lugan, ${ }^{\dagger}, *$ Vincent César ${ }^{\dagger} * *$ and Dmitry A. Valyaev ${ }^{\dagger}, *$ \\ $\dagger$ LCC-CNRS, Université de Toulouse, CNRS, UPS, 205 route de Narbonne, 31077 Toulouse Cedex 4, France \\ $\ddagger$ Kurnakov Institute of General and Inorganic Chemistry, Russian Academy of Sciences, 31 Leninsky Pr., Moscow, 119991, \\ Russia
}

$\S$ A. N. Nesmeyanov Institute of Organoelement Compounds (INEOS), Russian Academy of Sciences, 28 Vavilov str., GSP1, B-334, Moscow, 119991, Russia

\| Shemyakin-Ovchinnikov Institute of Bioorganic Chemistry, Russian Academy of Sciences, 16/10 Miklukho-Maklay Str., Moscow 117997, Russia

‡ Institut Universitaire de France, 1 rue Descartes, 75231 Paris Cedex 05, France

\begin{abstract}
The lithiation of the NHC ligand backbone in $\mathrm{Cp}(\mathrm{CO})_{2} \mathrm{Mn}$ (IMes) followed by transmetallation on the $\mathrm{C} 4$ carbenic position with $\mathrm{Cp}(\mathrm{CO})_{2} \mathrm{FeI}$ led to the heterobimetallic complex $\mathrm{Cp}(\mathrm{CO})_{2} \mathrm{Mn}(\mu-d \mathrm{IMes}) \mathrm{Fe}(\mathrm{CO})_{2} \mathrm{Cp}$ bearing the anionic ditopic imidazol2,4-diylidene $d \mathrm{IMes}$ ligand. Subsequent treatment of the later with $\mathrm{TfOH}$ induced a selective decoordination of the $\left[\mathrm{Cp}(\mathrm{CO})_{2} \mathrm{Mn}\right]$ fragment to form the cationic abnormal NHC complex $\left[\mathrm{Cp}(\mathrm{CO})_{2} \mathrm{Fe}(a \mathrm{IMes})\right](\mathrm{OTf})$, which was further derivatized into the bis(iron) $d \mathrm{IMes}$ complex $\left[\mathrm{Cp}(\mathrm{CO})_{2} \mathrm{Fe}(\mu-d \mathrm{IMes}) \mathrm{Fe}(\mathrm{CO})_{2} \mathrm{Cp}\right](\mathrm{OTf})$ by reaction with $t \mathrm{AmOK}$ and $\mathrm{Cp}(\mathrm{CO})_{2} \mathrm{FeI}$. The effect of the metallation at the $\mathrm{C} 4$ or $\mathrm{C} 2$ positions of imidazole ring on the electronic donation properties of the associated $\mathrm{C} 2$ and $\mathrm{C} 4$ carbenic centers in $d \mathrm{IMes}$ ligand was quantified through systematic experimental and theoretical studies of IMes, $a \mathrm{IMes}$ and $d \mathrm{IMes}$ complexes. The evaluation of the catalytic activity of the series of cationic Fe(II) complexes based on IMes, $a \mathrm{IMes}$, and $d \mathrm{IMes}$ ligands in a benchmark ketone hydrosilylation showed the superiority of the bimetallic derivative.
\end{abstract}

\section{INTRODUCTION}

Since their seminal preparation by Arduengo et al. in $1991^{1}$ stable $2 \mathrm{H}$-imidazol-2-ylidenes (A, Chart 1 ) became the most prominent class of $\mathrm{N}$-heterocyclic carbenes (NHCs). Ten years later Crabtree and coworkers reported the first examples of transition metal complexes bearing isomeric imidazol-4-ylidene ligands $(\mathbf{B})^{2}$ so called "abnormal" NHCs $(a \mathrm{NHCs})$, the first representative free $a \mathrm{NHC}$ being isolated in the group of Bertrand in 2009. ${ }^{3}$ Typically $a \mathrm{NHC}$ ligands show significantly stronger $\sigma$-donor properties than their "normal" NHC analogues and this characteristic feature was successfully exploited in some catalytic processes. ${ }^{4}$ In 2006 Arnold et al. reported the preparation of lanthanide complexes supported by a ditopic anionic imidazol-2,4-diylidene (NHDC, C) ligands exhibiting normal and abnormal carbenic functions. ${ }^{5}$ Shortly after Robinson and coworkers showed that lithium type C NHDC complexes could be readily obtained by backbone metallation of free NHCs A with $n \mathrm{BuLi}^{6}{ }^{6}$ Finally, Whittlesey and coworkers reported in 2007 the first complex bearing the ditopic anionic imidazol-4,5diylidene ligand $\mathbf{D}^{7}$ and more recently Ghadwal succeeded generating in situ the corresponding lithium dicarbene species, here by double metallation of 2-arylsubstituted imidazolium salts with two equivalents of $n \mathrm{BuLi}^{8}$

Chart 1. Different Types of Mono- and Ditopic NHCs Derived from Imidazolium Salts

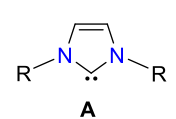

A
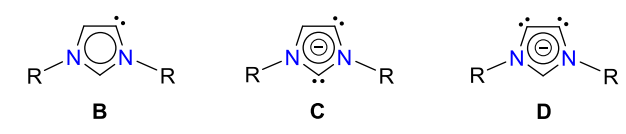

Though the chemistry of NHDC species $\mathbf{C}$ and their adducts with main group elements have been well developed, ${ }^{6,9,10}$ the corresponding binuclear transition metal complexes remain relatively scarce. Bimetallic $\mathrm{Zn}(\mathrm{II})^{11}$ and $\mathrm{Au}(\mathrm{I})^{12}$ NHDC derivatives based on IPr skeleton (IPr $=1,3$-bis(2,6-diisopropylphenyl)- $2 \mathrm{H}$-imidazol-2-ylidene) were originally obtained by transmetallation of main group metal cations in appropriate precursors with $\mathrm{ZnEt}_{2}$ and $\left(\mathrm{PPh}_{3}\right) \mathrm{AuCl}$, respectively. Another approach exploiting $\mathrm{C}-\mathrm{H}^{13}$ or $\mathrm{C}-\mathrm{I}^{14}$ NHC backbone bond activation in bidentate and pincer complexes resulted in the formation of binuclear $\mathrm{Pd}(\mathrm{II})$ or $\mathrm{Co}(\mathrm{I})$ NHDC complexes. Finally, a variety of heterobimetallic NHDC species associating $\mathrm{Ru}(\mathrm{II})$ to $\mathrm{Ag}(\mathrm{I}), \mathrm{Au}(\mathrm{I}), \mathrm{Pd}(\mathrm{II})$ or $\operatorname{Ir}(\mathrm{I})$ was prepared from cationic complexes $\left[\mathrm{Ru}\left(\kappa^{2}-\mathrm{OAc}\right)(\mathrm{L}-\mathrm{L})(a \mathrm{NHC}-\mathrm{P})\right] \mathrm{Br}(\mathrm{L}-\mathrm{L}=\mathrm{NHC}-$ phosphine, diphosphine), in which the $\mathrm{C} 2$ position of $a \mathrm{NHC}$ ligand remained accessible for metal coordination. ${ }^{15}$ Clearly, the lack of sufficiently general preparation methods still hamper the 
development of this chemistry and even the electronic properties of the NHC units in ditopic ligands $\mathbf{C}$ have never been fully quantified by experimental or theoretical means.

We have recently shown that the lithiation of the IMes ligand backbone (IMes = 1,3-bis(2,4,6-trimethylphenyl)-2 $\mathrm{H}$-imidazol2-ylidene) in the $\mathrm{Mn}(\mathrm{I})$ complex $\mathrm{Cp}(\mathrm{CO})_{2} \mathrm{Mn}(\mathrm{IMes})$ (1) with $n \mathrm{BuLi}$ leads to the quantitative formation of the stable complex $\mathrm{Cp}(\mathrm{CO})_{2} \mathrm{Mn}(\mu$-dIMes)Li (2) supported by an imidazol-2,4-diylidene ligand denoted here and below as $d \mathrm{IMes}$ (Scheme 1). ${ }^{16}$ The abnormal carbene function in $\mathbf{2}$ could readily undergo carboxylation, ${ }^{16}$ electrophilic fluorination, ${ }^{17}$ or oxidative coupling $^{18}$ processes to form the corresponding backbone-decorated IMes derivatives in good yield (Scheme 1, paths $i$-iii).

Scheme 1. Reactivity of the Abnormal Carbene Moiety in Complex Cp(CO) ${ }_{2} \mathrm{Mn}(\mu-d \mathrm{IMes}) \mathrm{Li}(2)$
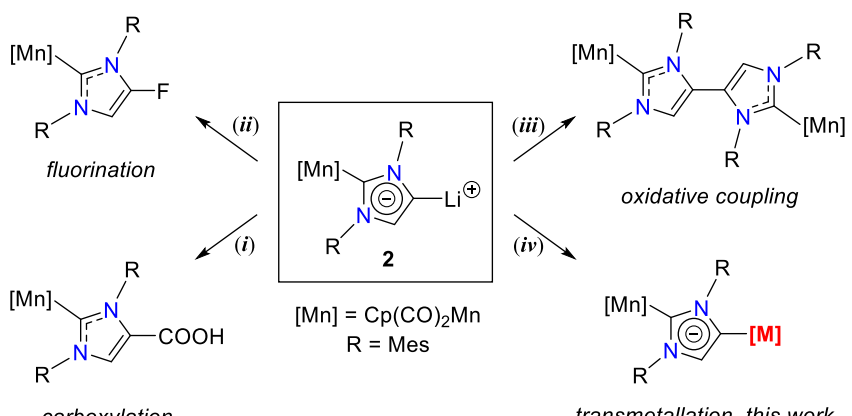

Inspired by the pioneering works of Robinson ${ }^{11}$ and Hevia ${ }^{12}$ we wondered whether transmetallation at the abnormal carbene position in complex 2 (Scheme 1, path $i v$ ) could afford a viable route to heterobimetallic transition metal NHDC complexes based on the ubiquitous IMes architecture. We report herein the synthesis of carbonyl-containing $\mathrm{Mn}$ (I) and Fe(II) NHDC complexes, the comprehensive study of their electronic structure and the quantification of the donation properties of $d$ IMes ligand. Finally the catalytic activity of a unique series of cationic $\mathrm{Fe}(\mathrm{II})$ complexes supported by the normal IMes (A), the abnormal $a \mathrm{IMes}(\mathbf{B})$ and the anionic ditopic $d \mathrm{IMes}(\mathbf{C})$ ligands (Chart $1, \mathrm{R}=$ Mes) was evaluated in benchmark ketone hydrosilylation.

\section{RESULTS AND DISCUSSION}

Synthesis and Characterization of $\mathrm{Mn}(\mathrm{I})$ and $\mathrm{Fe}(\mathrm{II}) \mathrm{NHC}$ Complexes Based on IMes, $\boldsymbol{a I M e s}$ and $\boldsymbol{d I M e s}$ Scaffolds. We were pleased to find that the reaction of compound $\mathbf{2}$ with $\mathrm{Cp}(\mathrm{CO})_{2} \mathrm{FeI}$ led to the formation of the corresponding binuclear complex $\mathrm{CpMn}(\mathrm{CO})_{2}(\mu-d \mathrm{IMes}) \mathrm{Fe}(\mathrm{CO})_{2} \mathrm{Cp}(3)$ in a good yield (Scheme 2). The manganese fragment attached to the normal NHC position in complex $\mathbf{3}$ was then selectively decoordinated upon protonation with triflic acid according to our recently developed protocol ${ }^{17,18}$ to afford the cationic $\mathrm{Fe}(\mathrm{II})$ complex $\left[\mathrm{Cp}(\mathrm{CO})_{2} \mathrm{Fe}(a \mathrm{IMes})\right](\mathrm{OTf})([4](\mathrm{OTf}))$ representing a rare example of mononuclear transition metal complex featuring aIMes ligand non-substituted at the $\mathrm{C} 2$ position. ${ }^{19,20}$ The later complex was further transformed into the binuclear bis(iron) $d$ IMes derivative $\quad\left[\mathrm{Cp}(\mathrm{CO})_{2} \mathrm{Fe}(\mu-d \mathrm{IMes}) \mathrm{Fe}(\mathrm{CO})_{2} \mathrm{Cp}\right](\mathrm{OTf})$ ([5]OTf) upon deprotonation of the $\mathrm{C} 2-\mathrm{H}$ bond of the imidazolium moiety with $t$ AmOK in the presence of $\mathrm{Cp}(\mathrm{CO})_{2} \mathrm{FeI}$. Finally, for the sake of comparison of spectral properties, and later on, of catalytic activities, the complex $\left[\mathrm{Cp}(\mathrm{CO})_{2} \mathrm{Fe}(\mathrm{IMes})\right]$
(OTf) ([6]OTf) (Scheme 2, inset) was prepared by an anion exchange in the known $\left[\mathrm{Cp}(\mathrm{CO})_{2} \mathrm{Fe}(\mathrm{IMes})\right] \mathrm{I}^{21}$ salt with NaOTf in $\mathrm{CH}_{2} \mathrm{Cl}_{2}$ /water.

Scheme 2. Synthesis of Normal, Abnormal and Ditopic NHC Complexes of $\mathrm{Mn}(\mathrm{I})$ and $\mathrm{Fe}(\mathrm{II})$. Mes = 2,4,6-Trimethylphenyl

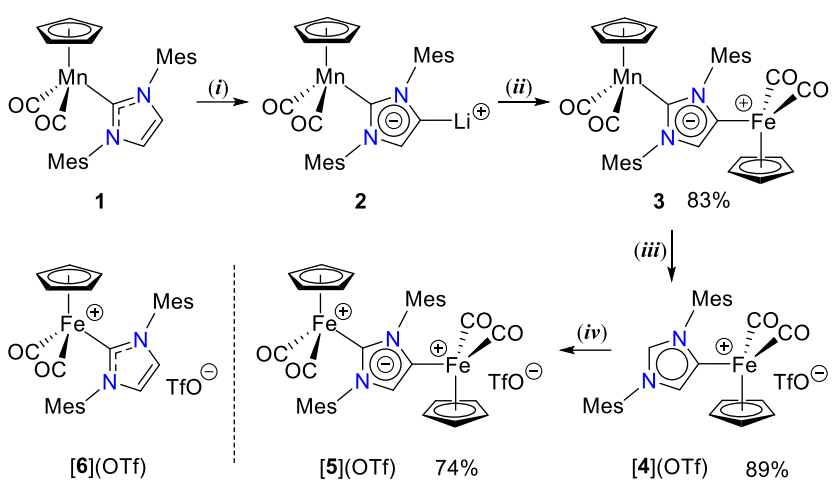

Reaction conditions: (i) 1.2 equiv. $n$ BuLi, THF, r.t., 15 min; (ii) $\mathrm{Cp}(\mathrm{CO})_{2} \mathrm{FeI}$, toluene, $-10^{\circ} \mathrm{C}$ to r.t., $0.5 \mathrm{~h}$; (iii) 1.2 equiv. $\mathrm{TfOH}$, $\mathrm{CH}_{2} \mathrm{Cl}_{2},-40^{\circ} \mathrm{C}$ to r.t., $0.5 \mathrm{~h}$; (iv) 1.5 equiv. $t \mathrm{AmOK}, \mathrm{Cp}(\mathrm{CO})_{2} \mathrm{FeI}$, THF, $-80^{\circ} \mathrm{C}$ to r.t., 1 h.

In contrast to the numerous examples of iron complexes supported by classic $2 \mathrm{H}$-imidazol-2-ylidene ligands, ${ }^{22}$ only a few compounds featuring imidazol-4-ylidene ligands are known to date. ${ }^{20 f-g, 23}$ The diamagnetic nature of our $\mathrm{NHC} \mathrm{Fe(II)} \mathrm{com-}$ plexes made possible their full characterization by ${ }^{1} \mathrm{H}$ and ${ }^{13} \mathrm{C}$ NMR spectroscopy (see Table 1 for selected pertinent NMR data). In particular, the signal of the backbone NHC proton of the $d$ IMes ligand in complex 3 is slightly shielded by $0.14 \mathrm{ppm}$ compared to the corresponding value in its IMes antecedent 1 in the same solvent $\left(\mathrm{C}_{6} \mathrm{D}_{6}\right)$. Similar trend is also observed within the $\mathrm{Fe}(\mathrm{II}) \mathrm{IMes} \rightarrow a \mathrm{IMes} \rightarrow d \mathrm{IMes}$ series showing the stepwise decrease of the corresponding $\delta_{\mathrm{H}}$ values by $c a .0 .3 \mathrm{ppm}$ in complexes [6](OTf), [4](OTf), and [5](OTf) (Table 1). The abnormal carbenic atoms coordinated to the $\mathrm{Fe}(\mathrm{II})$ centers in complexes 3, [4](OTf), and [5](OTf) are observed by ${ }^{13} \mathrm{C} \mathrm{NMR}$ spectroscopy in a range of $\delta_{\mathrm{C} 4} 124.8-141.8 \mathrm{ppm}$. Interestingly, the ${ }^{13} \mathrm{C}$ NMR signals belonging to both normal and abnormal carbene atoms in the cationic $d$ IMes complex [5]OTf are shifted by $c a .5 \mathrm{ppm}$ upfield compared to the corresponding signals in the mononuclear derivatives [6]OTf and [4]OTf. Similar difference for $\delta_{C 4}$ carbene resonance values in a range 4.4-12.3 ppm was also observed between related Ru(II) abnormal and NHDC complexes. ${ }^{15}$ The observed shielding of the backbone imidazolium protons and carbenic resonances in $d \mathrm{IMes}$ complexes can

Table 1. Selected ${ }^{1} \mathrm{H}$ and ${ }^{13} \mathrm{C}$ NMR Data for $\mathrm{Mn}(\mathrm{I})$ and Fe(II) Complexes Bearing Normal, Abnormal and Ditopic NHC Ligands

\begin{tabular}{llllll}
\hline Complex & $\delta_{C 5-H}$ & $\delta_{C 2}$ & $\delta_{C 4}$ & $\delta_{C 5}$ & $\delta_{C O}$ \\
\hline $\mathbf{1}^{a}$ & 6.18 & 205.4 & 123.8 & 123.8 & 234.4 \\
{$[\mathbf{6}](\mathrm{OTf})^{b}$} & 7.37 & 171.4 & 128.1 & 128.1 & 209.4 \\
{$[\mathbf{4}](\mathrm{OTf})^{b}$} & 7.07 & 138.2 & 141.8 & 132.2 & 211.8 \\
$\mathbf{3}^{a}$ & 6.04 & 204.4 & 124.8 & 132.9 & $235.1,213.8$ \\
{$[\mathbf{5}](\mathrm{OTf})^{b}$} & 6.79 & 166.7 & 136.6 & 135.7 & $212.7,210.3$ \\
\hline
\end{tabular}

${ }^{a} \mathrm{C}_{6} \mathrm{D}_{6}$ solution; ${ }^{b} \mathrm{CDCl}_{3}$ solution 
be ascribed to the higher electron density within the carbenic heterocycle, which is translated in chemical drawings by a formal negative charge delocalized inside the heterocycle.

X-ray diffraction study of the bimetallic NHDC complex 3. The molecular structure of the heterobimetallic complex 3 was established by single-crystal X-ray diffraction analysis (Figure 1). ${ }^{24}$ Both metal centers display an usual piano-stool coordination environment. While the Mn-NHC bond (2.0133(13) $\AA$ ) in $\mathbf{3}$ is slightly longer than the corresponding one in the parent IMes complex $1(2.003[3] \AA),{ }^{16}$ the $\mathrm{Fe}-a \mathrm{NHC}$ bond distance (1.9936(13) $\AA$ ) is the shortest among other reported anionic NHDC $(2.064(2)-2.110(2) \AA)^{23 b, c}$ or neutral monodentate $a \mathrm{NHC}$ iron complexes (2.026(3)-2.117(2) ^), ${ }^{20 \mathrm{~g}, 23 \mathrm{a}, \mathrm{d}}$ and compares well with those found in structurally similar $\mathrm{Fe}(\mathrm{II})$ halfsandwich 1,2,3-triazol-4-ylidene derivatives (1.9744(14)$2.010(6) \AA) .{ }^{25}$ The normal NHC moiety bonded to Mn1 atom adopts an almost ideal horizontal coordination mode ${ }^{26}\left(\mathrm{Cp}_{\mathrm{cnt}}{ }^{-}\right.$ Mn1-C2-N2 -80.94(12) ${ }^{\circ}$, whereas the abnormal one bonded to $\mathrm{Fe} 1$ atom shows an eclipsed conformation, in which the $\mathrm{NHC}$ ring becomes almost coplanar with one of the $\mathrm{CO}$ ligands $(\mathrm{C} 8$ Fe1-C4-N2 -23.04(13) $)^{\circ}$ bringing one of the mesityl group attached to the NHC ring in close proximity to carbonyl carbon atom C8 (C8...C31 3.0284(18) A). Actually, the combination of this $\mathrm{C}_{\text {ipso }} \ldots \mathrm{C} \equiv \mathrm{O}$ distance being inferior to the sum of the Van der Waals radii (3.4 $\AA$ ) and the significant bending of the adjacent $\mathrm{Fe}-\mathrm{C}-\mathrm{O}$ fragment (Fe1-C8-O8 172.30(12) ${ }^{\circ}$ vs. Fe1-C9-O9 $\left.178.46(13)^{\circ}\right)$ suggests the occurrence of an attractive interligand $\pi(\mathrm{C}=\mathrm{C}) \ldots \pi^{*}(\mathrm{C} \equiv \mathrm{O})$ interaction (vide infra) similar to the one previously evidenced in given Fischer-type and NHC complexes. $^{27}$

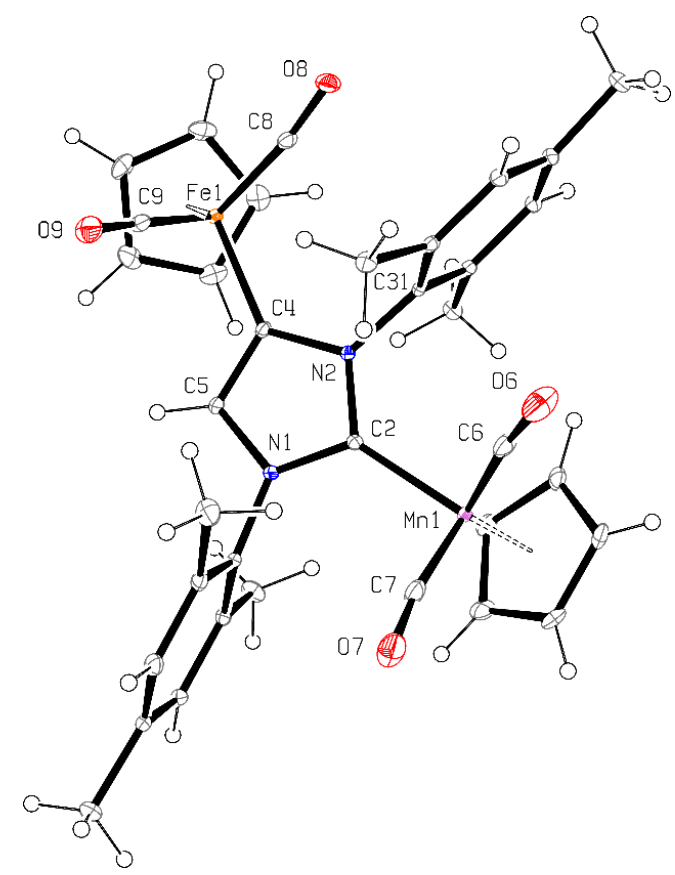

Figure 1. A perspective view of a complex 3 (30\% probability ellipsoids).

Theoretical Investigation of the Electronic Structure of Transition Metal $d$ IMes Complexes and the Comparison with Their Mononuclear Congeners. DFT optimized structures of all relevant $\mathrm{Mn}$ (I) and Fe(II) complexes obtained in the gas phase using G09/BP86-D3/def2-TZVP approach are pre- sented in Figure 2. The most pertinent structural data are provided in Table S1 (see the Supporting Information). While in the case of the $\mathrm{Fe}$ (II) $a$ IMes complex $\mathbf{4}^{+}$a single minimum was located on the potential energy surface, two minima were found for both neutral $\mathrm{Mn}$ (I) and cationic Fe(II) IMes complexes corresponding to two rotamers exhibiting either an horizontal (1a, $\left.\mathbf{6} \mathbf{a}^{+}\right)$or an eclipsed $\left(\mathbf{1 b}, \mathbf{6 b}^{+}\right)$NHC ligand coordination mode. The same situation was also observed in bimetallic NHDC derivatives $\mathbf{3}$ and $\mathbf{5}^{+}$(Figure 2). The calculated geometries of $\mathbf{1 b}$ and $\mathbf{3 a}$ show an excellent agreement with the corresponding solid-state structures of complexes $\mathbf{1}^{16}$ and $\mathbf{3}$ obtained by X-ray diffraction. Since the difference in main thermodynamic characteristics $\left(\Delta \mathrm{E}, \Delta \mathrm{H}^{298}\right.$ and $\left.\Delta \mathrm{G}^{298}\right)$ between these horizontal and eclipsed isomers (Table S2) does not exceed $1.6 \mathrm{kcal} \mathrm{mol}^{-1}$, it is not surprising that either one or both conformations have been observed by single crystal X-ray diffraction in parent
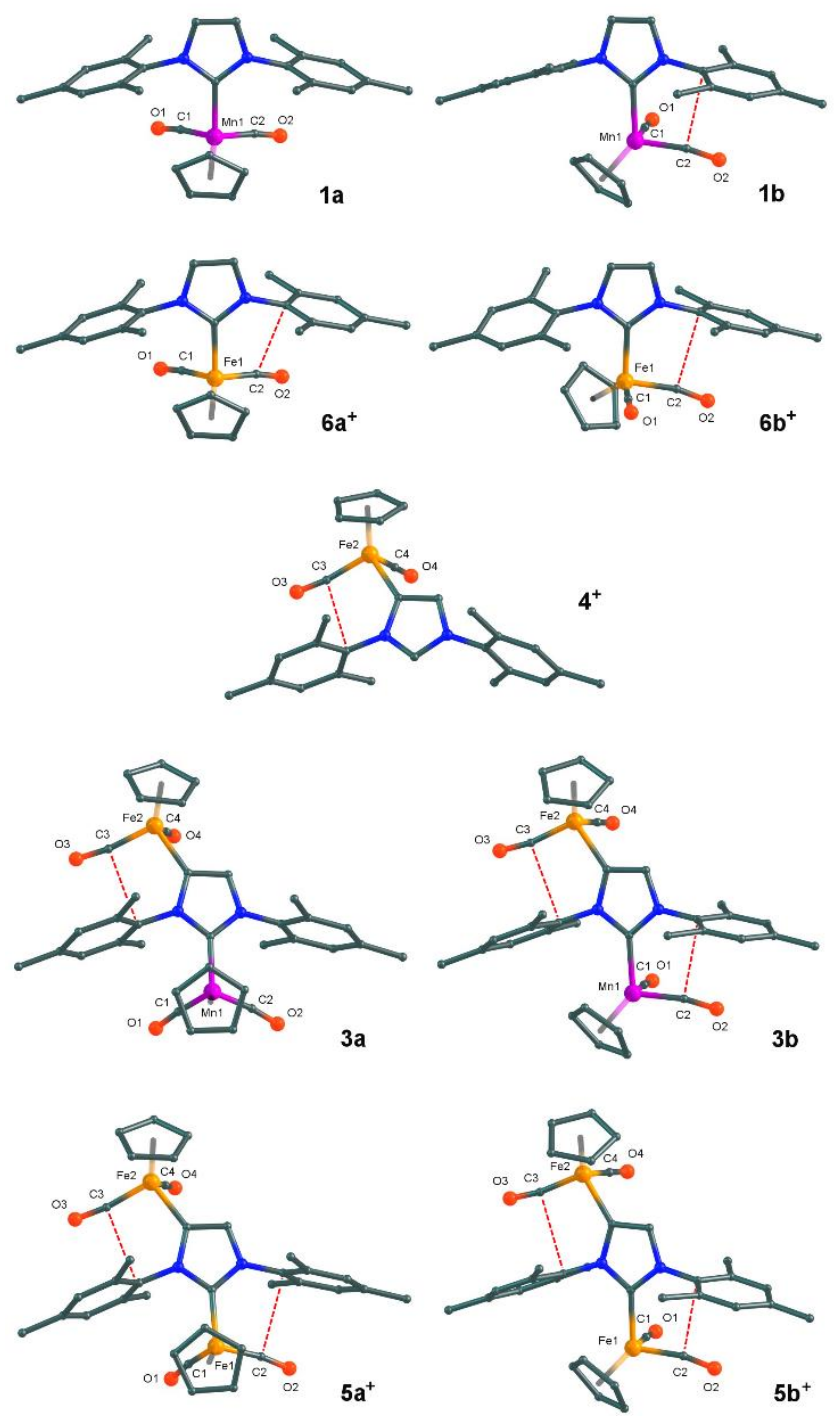

Figure 2. DFT optimized geometries for the cationic parts of $\mathrm{Mn}(\mathrm{I})$ and $\mathrm{Fe}(\mathrm{II})$ IMes, aIMes and $d \mathrm{IMes}$ complexes calculated at G09/BP86-D3/def2-TZVP level. Hydrogen atoms are omitted for clarity, color element codes: $\mathrm{C}-$ grey, $\mathrm{N}$ - blue, $\mathrm{O}-$ red, $\mathrm{Mn}$ - rose, $\mathrm{Fe}-$ orange. Non-covalent interligand $\pi(\mathrm{C}=\mathrm{C}) \ldots \pi^{*}(\mathrm{C} \equiv \mathrm{O})$ interactions detected by AIM approach are indicated by red dashed lines. 
$\left[\mathrm{Cp}(\mathrm{CO})_{2} \mathrm{M}(\mathrm{NHC})\right]^{\mathrm{n}+}\left(\mathrm{M}=\mathrm{Mn}, \mathrm{n}=0 ; ;^{16,18,28} \mathrm{M}=\mathrm{Fe}, \mathrm{n}=1^{29}\right)$ complexes bearing $\mathrm{N}$-aryl-substituted NHC ligands and these rotamers are likely to be in fast exchange in solution.

The calculated metal-NHC bond distances in the bimetallic $d$ IMes derivatives are systematically longer by 0.01-0.02 $\AA$ than those found in the corresponding conformers of mononuclear IMes and $a$ IMes complexes. Taking into account the presence of several short $\mathrm{C}_{i p s o} \ldots \mathrm{C} \equiv \mathrm{O}$ contacts and associated bent $\mathrm{M}-\mathrm{C}-\mathrm{O}$ fragments (Figure 2, Table S1) for both normal (2.779$\left.3.084 \AA, 166.96-172.43^{\circ}\right)$ and abnormal (2.891-2.932 $\AA$, $\left.169.34-171.29^{\circ}\right) \mathrm{Cp}(\mathrm{CO})_{2} \mathrm{M}-$ carbene moieties in these complexes, we investigated the possible occurrence of attractive interligand $\pi(\mathrm{C}=\mathrm{C}) \ldots \pi^{*}(\mathrm{C} \equiv \mathrm{O})$ interactions ${ }^{27}$ using Bader's Atoms In Molecules (AIM) theory ${ }^{30}$ (see for details Figures S14-18 and Table S3 in the Supporting information). While such interligand intramolecular interactions were found only for the eclipsed conformations of the $\mathrm{Cp}(\mathrm{CO})_{2} \mathrm{Mn}-\mathrm{NHC}$ moieties in $\mathbf{1 b}$ and $\mathbf{3 b}$ (Figure S14 and Figure S17, respectively) with an interaction energy $\mathrm{E}_{\text {int }}$ of $2.4 \mathrm{kcal} \mathrm{mol}^{-1}$ in both cases as estimated using the Espinosa-Molins-Lecomte correlation, ${ }^{31}$ they are present in all $\mathrm{Cp}(\mathrm{CO})_{2} \mathrm{Fe}-\mathrm{NHC}$ fragments regardless the $\mathrm{NHC}$ orientation (Figures S15-18), the interaction energy being in the 1.9-2.6 $\mathrm{kcal} \mathrm{mol}^{-1}$ range. According to the bond critical point (BCP) characteristics (Table S3) for the eclipsed conformations of $\mathrm{Fe}(\mathrm{II})$ IMes and $a \mathrm{IMes}$ fragments $\pi(\mathrm{C}=\mathrm{C}) \ldots \pi *(\mathrm{C} \equiv \mathrm{O})$ interactions are weaker in the latter case (2.6 vs. $\left.2.1-2.2 \mathrm{kcal} \mathrm{mol}^{-1}\right)$. Though the estimated interaction energies $\left(1.9-2.0 \mathrm{kcal} \mathrm{mol}^{-1}\right)$ found in case of horizontal conformers $5 \mathbf{a}^{+}$and $\mathbf{6 a}^{+}$formally seems to be comparable, these supramolecular bonds show very high values of ellipticity (1.074 and 1.303, respectively vs. 0.122 and 0.088 for the same type of bonding in eclipsed conformers $\mathbf{5} \mathbf{b}^{+}$and $\mathbf{6} \mathbf{b}^{+}$), which clearly indicate their strongly disturbed character.

In contrast to well-studied normal and abnormal carbene derivatives, to the best of our knowledge the electronic structure and bonding situation for bimetallic transition metal NHDC

Table 2. Selected AIM Charges and Bond Orders (BOs) for Optimized Structures of Mn(I) and Fe(II) Complexes Bearing Normal, Abnormal and Ditopic NHCs

\begin{tabular}{llll}
\hline Comp. & Metal charge & $\begin{array}{l}\text { NHC } \\
\text { charge }^{a}\end{array}$ & $\begin{array}{l}\text { BOs for M-NHC } \\
\text { bond }\end{array}$ \\
\hline $\mathbf{1 a}$ & $+0.948(\mathrm{Mn}-\mathrm{NHC})$ & -0.799 & $0.800(\mathrm{Mn}-\mathrm{NHC})$ \\
$\mathbf{1 b}$ & $+0.946(\mathrm{Mn}-\mathrm{NHC})$ & -0.806 & $0.813(\mathrm{Mn}-\mathrm{NHC})$ \\
$\mathbf{6 a}^{+}$ & $+0.845(\mathrm{Fe}-\mathrm{NHC})$ & -0.647 & $0.782(\mathrm{Fe}-\mathrm{NHC})$ \\
$\mathbf{6 b}^{+}$ & $+0.843(\mathrm{Fe}-\mathrm{NHC})$ & -0.649 & $0.779(\mathrm{Fe}-\mathrm{NHC})$ \\
$\mathbf{4}^{+}$ & $+0.840(\mathrm{Fe}-a \mathrm{NHC})$ & -0.616 & $0.799(\mathrm{Fe}-a \mathrm{NHC})$ \\
& $+0.951(\mathrm{Mn}-\mathrm{NHC})$ & -1.115 & $0.787(\mathrm{Mn}-\mathrm{NHC})$ \\
$\mathbf{3 a}$ & $+0.838(\mathrm{Fe}-a \mathrm{NHC})$ & & $0.791(\mathrm{Fe}-a \mathrm{NHC})$ \\
& $+0.947(\mathrm{Mn}-\mathrm{NHC})$ & -1.123 & $0.795(\mathrm{Mn}-\mathrm{NHC})$ \\
$\mathbf{3 b}$ & $+0.840(\mathrm{Fe}-a \mathrm{NHC})$ & & $0.787(\mathrm{Fe}-a \mathrm{NHC})$ \\
& $+0.845(\mathrm{Fe}-\mathrm{NHC})$ & -1.027 & $0.776(\mathrm{Fe}-\mathrm{NHC})$ \\
$\mathbf{5 a} \mathbf{a}^{+}$ & $+0.840(\mathrm{Fe}-a \mathrm{NHC})$ & & $0.792(\mathrm{Fe}-a \mathrm{NHC})$ \\
& $+0.844(\mathrm{Fe}-\mathrm{NHC})$ & -1.031 & $0.769(\mathrm{Fe}-\mathrm{NHC})$ \\
$\mathbf{5 b} \mathbf{b}^{+}$ & $+0.841(\mathrm{Fe}-a \mathrm{NHC})$ & & $0.789(\mathrm{Fe}-a \mathrm{NHC})$ \\
\hline
\end{tabular}

${ }^{a}$ total AIM charge of the heterocyclic moiety without aryl groups $\left(\mathrm{C}_{3} \mathrm{~N}_{2} \mathrm{H}_{2}\right.$ and $\mathrm{C}_{3} \mathrm{~N}_{2} \mathrm{H}_{1}$ for mono- and ditopic carbenes, respectively) complexes has never been investigated by theoretical means. Here, DFT calculations data show virtually the same AIM metal charges and metal-carbene bond orders (BOs) in all $\mathrm{Mn}(\mathrm{I})$ and $\mathrm{Fe}(\mathrm{II})$ IMes, $a$ IMes and $d$ IMes complexes as well as negatively charged $d$ IMes units in bimetallic species 3a-b and $\mathbf{5 a - \mathbf { b } ^ { + }}$ (Table 2). Similar trends in charge distribution can be also deduced from the data obtained by Natural Bond Orbitals (NBO) approach (Table S6).

The metal-carbene bonding in these species was investigated by energy decomposition analysis (EDA) ${ }^{32}$ (for details see Experimental section and Table S8 in the Supporting Information). The overall binding energy $\mathrm{E}_{\text {int }}$ of the $\mathrm{Fe}-\mathrm{NHC}$ bonds is $c a$. $50 \%$ higher than for the analogous $\mathrm{Mn}-\mathrm{NHC}$ interactions mainly due to significantly higher electrostatic contribution

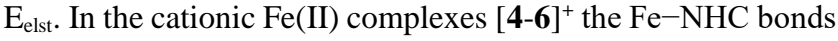
are always weaker by $3-4 \%$ than $\mathrm{Fe}-a \mathrm{NHC}$ ones again owing to slightly greater ionic character for the later, in agreement with literature data. ${ }^{33}$ Interestingly, binding energies for both $\mathrm{Fe}-\mathrm{NHC}$ and $\mathrm{Fe}-a \mathrm{NHC}$ bonds in $\mathbf{5}^{+}$are systematically $c a .6 \%$ greater than those found in mononuclear congeners $\mathbf{6}^{+}$and $\mathbf{4}^{+}$, respectively. The bonding parameters of iron- $a \mathrm{NHC}$ bonds in $d \mathrm{IMes}$ complexes $\mathbf{3}$ and $\mathbf{5}^{+}$were then compared with those of classic $\mathrm{Fe}-\mathrm{C} \sigma$-bonds in model $\mathrm{Fe}(\mathrm{II})$ complexes $\mathrm{Cp}(\mathrm{CO})_{2} \mathrm{Fe}-\mathrm{R}$ ( $\mathrm{R}=\mathrm{Me}, 2$ - and 4-imidazolyl). This study revealed the notable increase of both electrostatic $\mathrm{E}_{\text {elst }}$ component and $\sigma$-bonding contribution in $\mathrm{E}_{\text {orb }}$ energy in the series of $\mathrm{Fe}-a \mathrm{NHC} \rightarrow \mathrm{Fe}$-heteroaryl $\rightarrow \mathrm{Fe}-$ alkyl bonds (for details see the Supporting Information) thus being consistent with a dative nature of the $\mathrm{Fe}-a \mathrm{NHC}$ bonds in NHDC species differing significantly from mainly electrostatically-driven $\mathrm{Fe}-\mathrm{C}$ interactions with pronounced $\sigma$-character in model complexes. The overall results obtained in this theoretical investigation confirm that the NHDC (C, Chart 1) in transition metal complexes really behave as anionic $\mathrm{L}_{2}$-type ligands.

Experimental Measurement of Relative Electron Donating Properties of $d \mathrm{IMes}$ Ligand and the Rationalization of the Observed Effects by DFT Calculations. Having in hands the first examples of NHDC complexes with carbonyl-containing transition metal fragments in both normal and abnormal positions we then turned our attention to the evaluation of electronic donation properties of this type of NHC ligands by IR spectroscopy (Table 3, Figures 3-4). Strikingly, we have observed that in complex 3 the $v_{\mathrm{CO}}$ bands for $\left[\mathrm{Cp}(\mathrm{CO})_{2} \mathrm{Mn}\right]$ and $\left[\mathrm{Cp}(\mathrm{CO})_{2} \mathrm{Fe}\right]^{+}$moieties are shifted into lower frequency region to $c a .8 .5$ and $15 \mathrm{~cm}^{-1}$ compared to those of monodentate NHC analogues 1 and [4](OTf), respectively (Figure 3). A similar situation is found for the Fe(II) complex [5](OTf) (Figure 4) and notably the donicity of the $a \mathrm{NHC}$ moiety in $d$ IMes ligand was found to be sensitive to the nature of the organometallic fragment on the normal NHC position $\left(\left\langle v_{\mathrm{CO}}\right\rangle 2005.0\right.$ and 2014.3 $\mathrm{cm}^{-1}$ for 3 and [5](OTf), respectively) reflecting the occurrence of an efficient electronic delocalization across NHDC ligand scaffold.

DFT calculations of IR data for all these compounds (Table 3 ) confirm the initial $v_{\text {CO }}$ peaks attribution and show the expected low frequency shift for the conformers with intramolecular $\pi(\mathrm{C}=\mathrm{C}) \ldots \pi^{*}(\mathrm{C} \equiv \mathrm{O})$ interactions. ${ }^{27 \mathrm{c}}$ The comparison of calculated $v_{\mathrm{CO}}$ data between the $d \mathrm{IMes}$ complexes and their monocarbene congeners is fully consistent with the experimentally observed trends and $\Delta v_{\mathrm{CO}}$ values within the same series of rotamers were well reproduced. 
Table 3. Experimental $\left(\mathrm{CH}_{2} \mathrm{Cl}_{2}\right.$ Solution) and Calculated (G09/BP86-D3/Def2-TZVP, italic) IR Spectroscopy Data for $\mathrm{Mn}(\mathrm{I})$ and $\mathrm{Fe}(\mathrm{II})$ IMes, $a \mathrm{IM}$ es and $d \mathrm{IMes}$ Complexes (Average $<v_{\mathrm{co}}>$ Values Are Given in Parenthesis in Red and Blue for Experimental and Theoretical Data, Respectively)

\begin{tabular}{lll}
\hline Comp. & $\begin{array}{l}v_{\mathrm{CO}} \text { of } \\
\mathrm{Cp}(\mathrm{CO})_{2} \mathrm{M}-\mathrm{NHC}, \mathrm{cm}^{-1}\end{array}$ & $\begin{array}{l}v_{\mathrm{CO}} \text { of } \\
\mathrm{Cp}(\mathrm{CO})_{2} \mathrm{M}-a \mathrm{NHC}, \mathrm{cm}^{-1}\end{array}$ \\
\hline $\mathbf{1}$ & $1908.5,1836(\mathbf{1 8 7 2 . 3})$ & \\
$\mathbf{1 a}$ & $1923,1875(\mathbf{1 8 9 9})$ & - \\
$\mathbf{1 b}$ & $1922,1872(\mathbf{1 8 9 7})$ & \\
{$[\mathbf{6}](\mathrm{OTf})$} & $2050.5,2006.5(\mathbf{2 0 2 8 . 5})$ & \\
$\mathbf{6 a}^{+}$ & $2038,1999(\mathbf{2 0 1 8 . 5})$ & - \\
$\mathbf{6 b}^{+}$ & $2031,1993(\mathbf{2 0 1 2})$ & \\
{$[\mathbf{4}](\mathrm{OTf})$} & & $2044,1996(\mathbf{2 0 2 0})$ \\
$\mathbf{4}^{+}$ & & $2033,1993(\mathbf{2 0 1 3})$ \\
$\mathbf{3}$ & $1900.5,1827(\mathbf{1 8 6 7 . 8})$ & $2030,1980(\mathbf{2 0 0 5})$ \\
$\mathbf{3 a}$ & $1919,1873(\mathbf{1 8 9 6})$ & $2017,1975(\mathbf{1 9 9 6})$ \\
$\mathbf{3 b}$ & $1918,1869(\mathbf{1 8 9 3 . 5})$ & $2016,1974(\mathbf{1 9 9 5})$ \\
{$[\mathbf{5}](\mathrm{OTf})$} & $2044,1998(\mathbf{2 0 2 1})$ & $2037.5,1991(\mathbf{2 0 1 4 . 3})$ \\
$\mathbf{5 a ^ { + }}$ & $2034,1994(\mathbf{2 0 1 4})$ & $2026,1986(\mathbf{2 0 0 6})$ \\
$\mathbf{5} \mathbf{b}^{+}$ & $2029,1987(\mathbf{2 0 0 8})$ & $2023,1984(\mathbf{2 0 0 3 . 5})$ \\
\hline
\end{tabular}

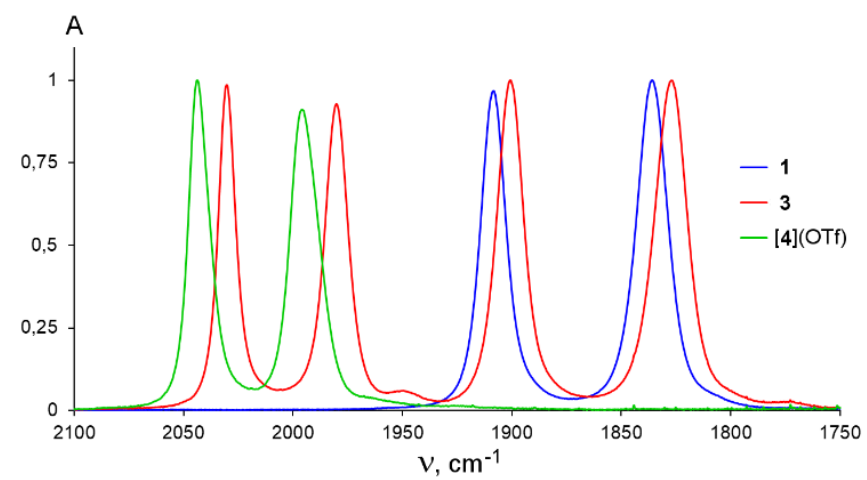

Figure 3. Superposition of normalized experimental IR spectra of complexes $\mathbf{1}, 3$ and [4](OTf) in $2100-1750 \mathrm{~cm}^{-1}$ range $\left(\mathrm{CH}_{2} \mathrm{Cl}_{2}, 0.5\right.$ $\mathrm{cm}^{-1}$ resolution).

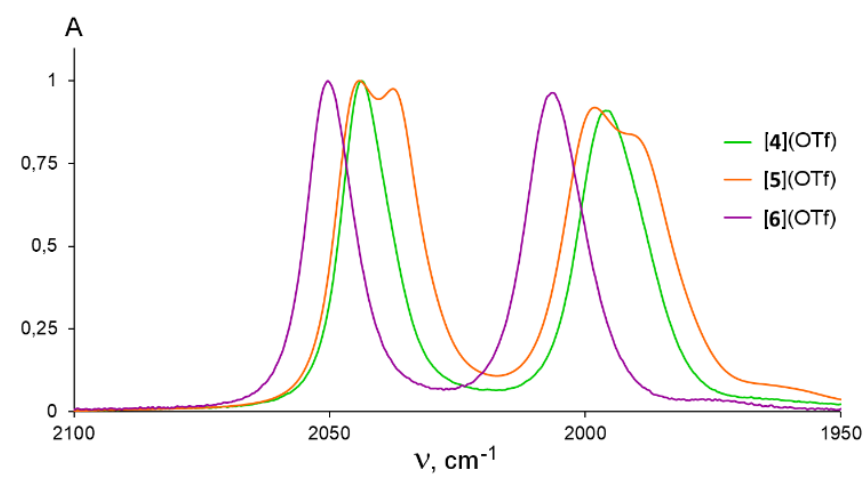

Figure 4. Superposition of normalized experimental IR spectra of complexes [4-6](OTf) in $2100-1950 \mathrm{~cm}^{-1}$ range $\left(\mathrm{CH}_{2} \mathrm{Cl}_{2}, 0.5 \mathrm{~cm}^{-1}\right.$ resolution)

These results seem to indicate that both carbene moieties of $d \mathrm{IMes}$ are more strongly electron donating than the corresponding normal (IMes) and abnormal (aIMes) NHCs (Scheme 3). This proposition is consistent with the decrease of medium $\left\langle v_{\mathrm{CO}}\right\rangle$ value for metal-NHC fragments observed by Tamm and coworkers in the rhodium-borane complex $\left(\mathrm{Et}_{4} \mathrm{~N}\right)\left[\left(\left(\mathrm{C}_{6} \mathrm{~F}_{5}\right)_{3} \mathrm{~B}\right)(\mu-d \mathrm{IPr})\left(\mathrm{Rh}(\mathrm{CO})_{2} \mathrm{Cl}\right)\right]\left(\left\langle v_{\mathrm{CO}}\right\rangle 2028 \mathrm{~cm}^{-1}\right)$ as compared to the classic IPr complex (IPr) Rh $(\mathrm{CO})_{2} \mathrm{Cl}\left(\left\langle v_{\mathrm{CO}}\right\rangle\right.$ $\left.2038 \mathrm{~cm}^{-1}\right) .{ }^{34} \mathrm{We}$ also previously observed similar low frequency shift of $v_{\mathrm{CO}}$ bands in IR spectra of manganese complexes $\mathrm{Cp}(\mathrm{CO})_{2} \mathrm{Mn}$ (IMes) $\left(\left\langle v_{\mathrm{CO}}\right\rangle 1885 \mathrm{~cm}^{-1}\right)$ as compared to $\left.\mathrm{Cp}(\mathrm{CO})_{2} \mathrm{Mn}(\mu-d \mathrm{IMes}) \mathrm{Li}\left(<v_{\mathrm{CO}}\right\rangle 1871 \mathrm{~cm}^{-1}\right)$ in $\mathrm{Et}_{2} \mathrm{O}$ solution. ${ }^{16}$

Scheme 3. The Fragmentation Method Used for the Comparison of Electronic Donation of Anionic $d$ IMes Ligand with Those of Related Neutral IMes and aIMes Carbenes $\left(\mathrm{R}=\mathrm{Mes},[\mathrm{M}]=\mathrm{Cp}(\mathrm{CO})_{2} \mathrm{Mn}, \mathrm{Cp}(\mathrm{CO})_{2} \mathrm{Fe}\right)$<smiles></smiles><smiles></smiles>

Yet, taking into account that IR measurements for NHC donicity determination are typically carried out on square-planar $\mathrm{Rh}(\mathrm{I})$ or $\operatorname{Ir}(\mathrm{I})$ complexes and directly correlated with Tolman's electronic parameter (TEP) ${ }^{35}$ and being aware of the possible $v_{\mathrm{CO}}$ response perturbations due to interligand interactions in halfsandwich carbene complexes, ${ }^{27 c}$ we decided to further assess our conclusions by another experimental method. Indeed, the measurement of the oxidation potential of metal NHC complexes constitutes an alternative, which could provide sometimes even higher precision than the TEP approach. ${ }^{36}$ While cyclic voltammogram (CV) of $\mathrm{Mn}(\mathrm{I})$ IMes complex 1 in acetonitrile reveals a fully reversible one electron oxidation at $\mathrm{E}_{1 / 2}\{\mathrm{Mn}(\mathrm{I}) / \mathrm{Mn}(\mathrm{II})\}=-$ $0.26 \mathrm{~V} v s$. Fc (Figure S9), its cationic Fe(II) analogue [6](OTf) undergoes under the same conditions an irreversible oxidation at $\mathrm{E}_{\text {p.a. }}\{\mathrm{Fe}(\mathrm{II}) / \mathrm{Fe}(\mathrm{III})\}=+1.44 \mathrm{~V}$ (Figure S13) probably due to the occurrence of $E C E$-type process rather typical for this coordinating solvent. ${ }^{37}$ The electrochemical behavior of Fe(II) aIMes derivative $[4](\mathrm{OTf})$ was found to be intermediate compared to its normal IMes analogues and a quasi-reversible $\left(\mathrm{I}_{\mathrm{a}} / \mathrm{I}_{\mathrm{c}}=0.6\right)$ one electron oxidation wave was observed at $\mathrm{E}_{1 / 2}\{\mathrm{Fe}(\mathrm{II}) / \mathrm{Fe}(\mathrm{III})\}=$ $+1.12 \mathrm{~V}$ (Figure S11) in full agreement with a stronger donation of the $a \mathrm{IMes}$ ligand. The analysis of CVs for $d \mathrm{IMes}$ complexes (Figures S10 and S12) reveals a similar electrochemical behavior accompanied by a significant decrease of the oxidation potentials for both normal (3: $\mathrm{E}_{1 / 2}\{\mathrm{Mn}(\mathrm{I}) / \mathrm{Mn}(\mathrm{II})\}=-0.39 \mathrm{~V}$; [5](OTf): $\left.\mathrm{E}_{\text {p.a. }}\{\mathrm{Fe}(\mathrm{II}) / \mathrm{Fe}(\mathrm{III})\}=+1.34 \mathrm{~V}\right)$ and especially for abnormal metal-NHC fragments (3: $\mathrm{E}_{1 / 2}\{\mathrm{Fe}(\mathrm{II}) / \mathrm{Fe}(\mathrm{III})\}=+0.71 \mathrm{~V}$; [5](OTf): $\left.\mathrm{E}_{1 / 2}\{\mathrm{Fe}(\mathrm{II}) / \mathrm{Fe}(\mathrm{III})\}=+0.86 \mathrm{~V}\right)$. Similarly, a significant decrease of $\mathrm{Ru}(\mathrm{II}) / \mathrm{Ru}(\mathrm{III})$ oxidation potential in binuclear RuIr NHDC complex containing the ruthenium atom coordinated to the abnormal NHC position was very recently attributed to the result of efficient electronic coupling via the NHDC ligand. ${ }^{15 a}$ Though an irreversible electrochemical behavior of normal $\left[\mathrm{Cp}(\mathrm{CO})_{2} \mathrm{Fe}(\mathrm{NHC})\right]^{+}$moieties precludes a full comparison within the series, lower oxidation potentials observed in the bimetallic $d$ IMes complexes reflect the increased donation properties of ditopic carbene ligand thus being in a perfect agreement with the data obtained by IR spectroscopy.

Though this remarkable boosting of the donation properties in NHDC ligands can be intuitively understood in terms of the delocalization of a formal anionic charge within the NHC core, we were pleased to rationalize this phenomenon using theoretical chemistry, namely through the extended transition state natural orbitals for chemical valence (ETS-NOCV) approach. ${ }^{38}$ 
The summary of the most relevant data for metal-NHC bonding analysis are presented in Table 4 (for details see Table S8 in the Supporting Information). The ETS-NOCV analysis for $\mathrm{Mn}(\mathrm{I})$ complex 1a revealed three primary channels (Figure 5) responsible for IMes $\sigma$-donation and two types of $\pi$-back bonding orthogonal and coplanar to the NHC ligand plane further denoted as $\pi_{\perp}$ and $\pi_{\|}$, respectively. While the major $\pi_{\perp}$ component represents a classic back-donation to the $\pi^{*}$ orbital of carbene, the minor $\pi_{\|}$can be described as an overlap of filled metal orbitals with the anti-bonding $\sigma^{*}$ orbitals of the NCN moiety.
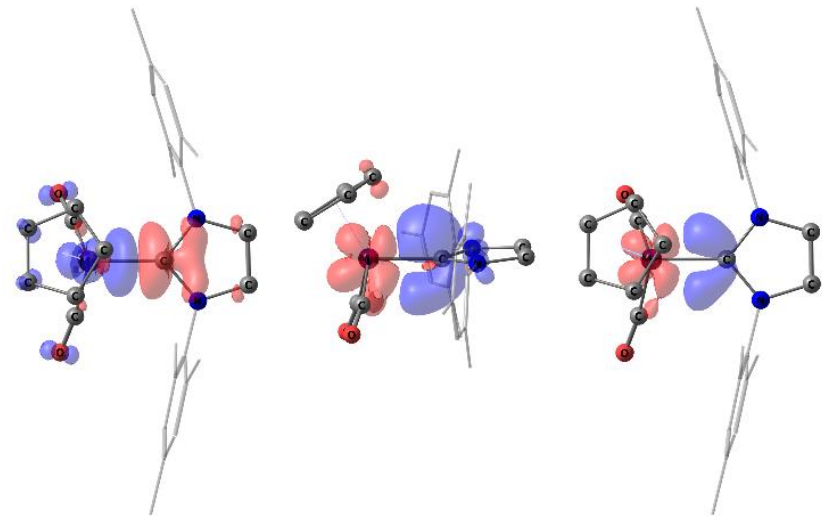

Figure 5. Electron deformation density corresponding to primary NOCV channels for $\mathrm{Mn}(\mathrm{I})$ complex $1 \mathrm{a}$ responsible for $\sigma$-donation (left) and two types of $\pi$-back donation $-\pi_{\perp}$ (center) and $\pi_{\|}$(right). Isosurfaces set at 0.003 and 0.001 a.u. for $\sigma$ - and $\pi$-bonding, respectively. Red and blue areas correspond to electron density depletion and concentration, respectively.

Table 4. Associated Energies of Primary NOCV Channels (kcal mol-1) Responsible for the $\sigma$-Donation and $\pi$-Back Bonding of NHC Ligands in $\mathrm{Mn}(\mathrm{I})$ and $\mathrm{Fe}(\mathrm{II})$ Complexes Bearing IMes, $a$ IMes and $d I M e s$ Ligands (ADF/BP86D3/TZP)

\begin{tabular}{lll}
\hline Comp. & $\mathrm{Cp}(\mathrm{CO})_{2} \mathrm{M}-\mathrm{NHC}$ bond & $\mathrm{Cp}(\mathrm{CO})_{2} \mathrm{M}-a \mathrm{NHC}$ bond \\
\hline $\mathbf{1 a}$ & $\sigma 38.0, \pi_{\perp} 12.5, \pi_{\|} 5.7$ & - \\
$\mathbf{1 b}$ & $\sigma 38.8, \pi_{\perp} 13.9, \pi_{\|} 5.4$ & - \\
$\mathbf{6 a}^{+}$ & $\sigma 54.3, \pi_{\perp} 9.6, \pi_{\|} 3.8$ & - \\
$\mathbf{6 b}^{+}$ & $\sigma 54.9, \pi_{\perp} 9.8, \pi_{\|} 4.1^{a}$ & - \\
$\mathbf{4}^{+}$ & - & $\sigma 64.8, \pi_{\perp} 9.1, \pi_{\|} 4.4$ \\
& & $\sigma 78.2, \pi_{\perp} 8.7$, \\
$\mathbf{3 a}$ & $\sigma 38.6, \pi_{\perp} 11.2, \pi_{\|} 5.7$ & $\pi 1 \| 2.5, \pi_{2 \|} 2.8^{b}$ \\
$\mathbf{3 b}$ & $\sigma 39.4, \pi_{\perp} 12.9, \pi_{\|} 5.5$ & $\sigma 77.9, \pi_{\perp} 8.9, \pi_{\|} 3.5^{c}$ \\
$\mathbf{5 a}^{+}$ & $\sigma 57.3, \pi_{\perp} 9.2, \pi_{\|} 4.1$ & $\sigma 71.5, \pi_{\perp} 8.7, \pi_{\|} 3.2$ \\
$\mathbf{5 b}^{+}$ & $\sigma 57.5, \pi_{\perp} 9.9, \pi_{\|} 4.1^{d}$ & $\sigma 71.3, \pi_{\perp} 9.0, \pi_{\|} 3.4$ \\
\hline
\end{tabular}

${ }^{a}$ Additional NOCV channel related to metal- $a \mathrm{NHC} \pi$-bonding with the associated energy of $2.2 \mathrm{kcal} . \mathrm{mol}^{-1}$ was also found (see Figure S25). ${ }^{b}$ In this case $\pi \|$ bonding was split in two components and one more NOCV channel related to metal- $a$ NHC $\pi$-bonding with the associated energy of $4.2 \mathrm{kcal}^{\mathrm{mol}} \mathrm{m}^{-1}$ was also found (see Figure S29). ${ }^{c}$ Additional NOCV channel related to metal- $a$ NHC $\pi$ bonding with the associated energy of $4.0 \mathrm{kcal}^{\mathrm{mol}}{ }^{-1}$ was also found (see Figure S30). ${ }^{d}$ Additional NOCV channel related to metal- $a$ NHC $\pi$-bonding with the associated energy of 2.4 kcal.mol ${ }^{-1}$ was also found (see Figure S32).
The associated energies of NOCV channels for 1a (Table 4) are close to calculated alkyl-substituted complex $\mathrm{Cp}(\mathrm{CO})_{2} \mathrm{Mn}(\mathrm{IMe})$ having the same horizontal orientation of the NHC ligand $\left(\sigma 35.0, \pi_{\perp} 14.1, \pi_{\|} 5.3 \mathrm{kcal} \mathrm{mol}^{-1}\right){ }^{39}$ For the eclipsed isomer $\mathbf{1 b}$, the energy values for $\sigma$ and $\pi_{\perp}$ components are a little bit higher reflecting slightly stronger $\mathrm{Mn}-\mathrm{NHC}$ bonding (see Table 2 for the bond orders) and additional NOCV channel responsible for $\pi(\mathrm{C}=\mathrm{C}) \ldots \pi^{*}(\mathrm{CO})$ interligand interaction having the associated energy of $1.5 \mathrm{kcal} \mathrm{mol}^{-1}$ was found (Figure S23). In Fe(II) complexes $\mathbf{6 a}^{+}$and $\mathbf{6 b}^{+}$IMes ligand displays a much stronger $\sigma$-bonding energy with a slightly reduced back-donation, which can be explained by a more electron deficient nature of the $\left[\mathrm{Cp}(\mathrm{CO})_{2} \mathrm{Fe}\right]^{+}$fragment compared to $\left[\mathrm{Cp}(\mathrm{CO})_{2} \mathrm{Mn}\right]$. As expected, the $a \mathrm{IMes}$ ligand in $\mathrm{Fe}(\mathrm{II})$ derivative $4^{+}$shows much greater $\sigma$-contribution with again slightly reduced $\pi_{\perp}$-bonding being both consistent with higher overall donation properties of $a \mathrm{NHCs} v s$. their normal isomers. These results are in agreement with the ETS-NOCV analysis of the bonding of the simplest NHC ligand models IMe and $a \mathrm{IMe}$ with different transition metal fragments. ${ }^{40}$ The energies of NOCV channels responsible for $\pi(\mathrm{C}=\mathrm{C}) \ldots \pi *(\mathrm{CO})$ interactions in $\mathrm{Fe}(\mathrm{II})$ NHC cations (3.3-4.3 $\left.\mathrm{kcal} \mathrm{mol}^{-1}\right)$ are significantly higher than in the corresponding neutral $\mathrm{Mn}(\mathrm{I})$ species being consistent with the results of AIM analysis (vide supra).

Noteworthy, the data obtained for the dIMes complexes within the same series of isomers (Table 4 ) show a simultaneous increase of the $\sigma$-donation and diminution of the $\pi$-backdonation for both $\mathrm{M}-\mathrm{NHC}$ and $\mathrm{M}-a \mathrm{NHC}$ bonding, which is especially pronounced in the latter case for the abnormal carbene fragment. Though the energy differences in most cases are not very significant, the synergy of both effects is clearly responsible for the experimentally observed amplification of NHC donor properties in NHDC derivatives.

Evaluation of Cationic Fe(II) Complexes Bearing IMes, $a$ IMes and $d$ IMes Ligands in Ketone Hydrosilylation Catalysis. In order to look at the possible incidence of improved donation properties of $d$ IMes ligand we tested a series of cationic $\mathrm{Fe}$ (II) complexes [4-6](OTf) in benchmark hydrosilylation of carbonyl substrates. ${ }^{41}$ These transformations are well known for half-sandwich $\mathrm{Fe}$ (II) complexes bearing normal ${ }^{22 \mathrm{a}, \mathrm{b}}$ and abnormal $^{23 a, 25}$ carbene ligands and we have already observed a beneficial effect of increased NHC donation on the catalytic performance in such processes. ${ }^{27 \mathrm{~b}} \mathrm{We}$ have chosen as a model the hydrosilylation of 2-acetonaphtone with $\mathrm{PhSiH}_{3}$ (Scheme 4) under the same conditions as previously reported for abnormal 1,2,3triazol-4-ylidene Fe(II) complex. ${ }^{25}$

Scheme 4. Evaluation of Cationic Fe(II) Complexes [4-6](OTf) in Hydrosilylation of 2-Acetonaphtone

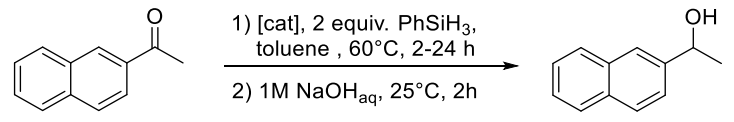

To our delight, in the presence of $1 \mathrm{~mol} \%$ of $d \mathrm{IMes}$ complex [5](OTf) a quantitative substrate conversion was achieved after $2 \mathrm{~h}$ at $60^{\circ} \mathrm{C}$ and the corresponding alcohol was isolated in $92 \%$ yield after hydrolysis. A decrease of the catalyst charge to 0.5 mol \% revealed $94 \%$ substrate conversion after $8 \mathrm{~h}$ under the same conditions. At the same time $a$ IMes complex [4](OTf) was found to be much less active affording only $60 \%$ conversion after $24 \mathrm{~h}$ at $1 \mathrm{~mol} \%$ loading and complex [6](OTf) bearing IMes ligand was totally inactive. To the best of our knowledge, this preliminary study represents the first example 
of direct comparison of the catalytic performance for transition metal complexes bearing structurally related normal, abnormal and ditopic NHCs. ${ }^{42,43}$

\section{CONCLUSION}

We have shown that bimetallic transition metal complexes based on imidazol-2,4-diylidene scaffold can be prepared from the emblematic IMes by a rational stepwise metallation approach using $\left[\mathrm{Cp}(\mathrm{CO})_{2} \mathrm{Mn}\right]$ moiety as protecting group for $\mathrm{C} 2$ carbene position. This gave access to an homogeneous series of cationic Fe(II) complexes bearing IMes, $a$ IMes, and $d$ IMes ligands allowing to show that the donation properties of both normal and abnormal carbenic moieties are actually increased by the metallation at the $\mathrm{C} 4$ and $\mathrm{C} 2$ positions, respectively. This effect was rationalized by a theoretical study using the ETSNOCV approach in terms of a simultaneous increase of $\sigma$-donation and decrease of $\pi$-backdonation being especially pronounced for the abnormal carbenic part. The evaluation of the catalytic properties of the singular series of monometallic Fe(II) IMes and $a$ IMes complexes, and bimetallic Fe(II) $d$ IMes complex in benchmark ketone hydrosilylation revealed the superiority of the derivative bearing the ditopic $d$ IMes ligand. We hope that this contribution will further stimulate the interest to NHDC complexes in the context of homogeneous catalysis.

\section{EXPERIMENTAL SECTION}

General considerations. All manipulations were carried out using Schlenk techniques under an atmosphere of dry nitrogen. Dry and oxygen-free organic solvents (THF, $\mathrm{Et}_{2} \mathrm{O}, \mathrm{CH}_{2} \mathrm{Cl}_{2}$, toluene, pentane) were obtained using LabSolv (Innovative Technology) solvent purification system. Acetonitrile for the electrochemical studies was dried by refluxing over $\mathrm{P}_{2} \mathrm{O}_{5}$ and distilled under argon prior to use. Solvents used for the purification of organometallic complexes by column chromatography (hexane, toluene, $\mathrm{CH}_{2} \mathrm{Cl}_{2}$, THF) were deoxygenated by nitrogen bubbling during 15-20 min. Deuterated chloroform for NMR experiments was passed through a short column of basic alumina, deoxygenated by three freeze-pump-thaw cycles and kept over $4 \AA$ molecular sieves. A liquid nitrogen/ethanol slush bath was used to maintain samples at the desired low temperature. Chromatographic purification of the compounds was performed on silica $(0.060-0.200 \mathrm{~mm}, 60 \AA)$ obtained from Acros Organics. Complexes $\mathrm{Cp}(\mathrm{CO})_{2} \mathrm{Mn}(\mathrm{IMes})(\mathbf{1}),{ }^{16}$ $\left[\mathrm{Cp}(\mathrm{CO})_{2} \mathrm{Fe}(\mathrm{IMes})\right] \mathrm{I}^{21}$ and $\mathrm{Cp}(\mathrm{CO})_{2} \mathrm{FeI}^{44}$ were prepared according to literature procedures. All other reagent grade chemicals purchased from commercial sources were used as received.

Solution IR spectra were recorded in $0.1 \mathrm{~mm} \mathrm{CaF}_{2}$ cells with 0.5 $\mathrm{cm}^{-1}$ resolution using a Perkin Elmer Frontier FT-IR spectrometer and given in $\mathrm{cm}^{-1}$ with relative intensity in parentheses. ${ }^{1} \mathrm{H}$ and ${ }^{13} \mathrm{C} \mathrm{NMR}$ spectra were obtained on Bruker Avance 400 or Avance III HD 400 spectrometers and referenced against the residual signals of deuterated solvents. ${ }^{45}$ The signals of quaternary carbon atoms in ${ }^{13} \mathrm{C}$ NMR spectra were attributed using JMOD and gated ${ }^{13} \mathrm{C}$ experiments. High-resolution mass spectra (ESI positive mode) were obtained using a Xevo G2 QTof (Waters) spectrometer. Elemental analyses were carried out at the LCC-CNRS (Toulouse) using a Perkin Elmer 2400 series II analyzer.

Cyclic voltammetry and squarewave voltammetry studies were performed using an Autolab PGSTAT100 instrument controlled by GPES 4.09 software in a three-electrode cell consisting of a Pt working electrode $(\mathrm{d}=0.5 \mathrm{~mm})$, a platinum wire $\left(\mathrm{S}=1 \mathrm{~cm}^{2}\right)$ as counter electrode, and a $S C E$ electrode as a reference, under Ar atmosphere in acetonitrile solution. $0.1 \mathrm{M}$ solution of $\mathrm{Bu}_{4} \mathrm{NPF}_{6}$ was used as the supporting electrolyte and sample concentrations were $1 \times 10^{-3} \mathrm{M}$. All peak potentials are calibrated relative to the ferrocene/ferrocenium couple $(\mathrm{E}=+0.40$ $\mathrm{V}$ vs. $S C E$ in $\mathrm{MeCN})^{46}$ by adding ferrocene at the end of the experiments.

Synthesis of complex 3. To a solution of complex 1 (640 mg, 1.33 $\mathrm{mmol})$ in THF ( $5 \mathrm{~mL})$ a $1.6 \mathrm{M}$ solution of $n \mathrm{BuLi}(1.0 \mathrm{~mL}, 1.6 \mathrm{mmol}$, 1.2 equiv.) was added dropwise at room temperature. After stirring for
15 min the resulting deep orange solution of complex 2 was evaporated under vacuum and the yellow-brown residue was dissolved in toluene $(5 \mathrm{~mL})$. The resulting solution of 2 was then added dropwise for $c a .15$ min under vigorous stirring to a solution of $\mathrm{Cp}(\mathrm{CO})_{2} \mathrm{FeI}(404 \mathrm{mg}, 1.33$ mmol, 1.0 equiv.) in toluene $(5 \mathrm{~mL})$ at $-10{ }^{\circ} \mathrm{C}$. The cooling bath was removed and the reaction mixture was allowed to reach room temperature. The volatiles were removed under vacuum and the orange residue was purified by column chromatography on silica $(2 \times 15 \mathrm{~cm})$. The first elution with 1:1 hexane/toluene mixture afforded yellow band containing traces of $\mathrm{Cp}(\mathrm{CO})_{2} \mathrm{FeI}$ and starting complex 1 (discarded), followed by a broad orange band of the product 3 contaminated with traces of $\left[\mathrm{Cp}(\mathrm{CO})_{2} \mathrm{Fe}\right]_{2}$ eluted with 95:5 toluene/ether mixture. The eluate was evaporated under vacuum and the residue was dissolved in 1:1 $\mathrm{THF} /$ heptane mixture $(c a .50 \mathrm{~mL}$ ). The solution was filtered through Celite and concentrated to $c a$. $20 \mathrm{~mL}$ under vacuum to induce the crystallization of the target product finished at $-20{ }^{\circ} \mathrm{C}$ overnight. The supernatant was removed by decantation and the precipitate was washed with hexane $(2 \times 10 \mathrm{~mL})$ and dried under vacuum to afford complex 3 (725 mg, 83\%) as orange microcrystalline solid. Single crystals suitable for X-Ray diffraction experiment were obtained by slow vapor diffusion of hexane into the solution of complex $\mathbf{3}$ in ether at room temperature. ${ }^{1} \mathrm{H}$ NMR $\left(400.1 \mathrm{MHz}, \mathrm{C}_{6} \mathrm{D}_{6}, 25^{\circ} \mathrm{C}\right): \delta 6.99$ (s, 2H, CHMes), 6.97 (s, 2H, CH $\left.H_{\text {Mes }}\right), 6.04$ (s, 1H, CHIm-5), 4.09 (s, 5H, Cp-Fe), 3.89 (s, 5H, $\mathrm{Cp}-\mathrm{Mn}$ ), 2.28 (s, 3H, CH3 o-Mes), 2.23 (s, 9H, $\mathrm{CH}_{3}$ o-Mes), 2.08 (s, 6H, $\left.\mathrm{CH}_{3 p \text {-Mes }}\right) ;{ }^{13} \mathrm{C}\left\{{ }^{1} \mathrm{H}\right\}$ NMR $\left(100.6 \mathrm{MHz}, \mathrm{C}_{6} \mathrm{D}_{6}, 25^{\circ} \mathrm{C}\right): \delta 235.1(\mathrm{Mn}-\mathrm{CO})$, 213.8 ( $\mathrm{Fe}-\mathrm{CO}), 204.4\left(\mathrm{Mn}-\mathrm{CN}_{2}\right), 142.5,139.7$ ( $\left.\mathrm{C}_{i \text {-Mes }}\right), 138.1,137.9$ (C- $\left.\mathrm{CH}_{3 p \text {-Mes }}\right), 137.6,136.3\left(C-\mathrm{CH}_{3 o \text {-Mes }}\right), 132.9\left(C \mathrm{H}_{\mathrm{Im}-5}\right), 129.6,129.3$

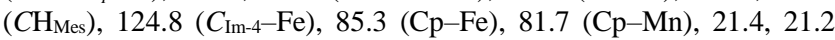
( $\mathrm{CH}_{3}$ p-Mes $), 19.2,18.8$ ( $\mathrm{CH}_{3}$ o-Mes $)$. IR $\left(\mathrm{CH}_{2} \mathrm{Cl}_{2}\right): v_{\mathrm{CO}} 2030.0$ (s), 1980.0 (s), $1900.5(\mathrm{~s}), 1827.0(\mathrm{~s}) \mathrm{cm}^{-1}$. Elemental analysis calculated (\%) for $\mathrm{C}_{35} \mathrm{H}_{33} \mathrm{FeMnN}_{2} \mathrm{O}_{4}$ : C, 64.05; H, 5.05; N, 4.25; found: C, 64.05; H, 5.30; $\mathrm{N}, 4.14$.

Synthesis of complex [4](OTf). To a solution of complex 3 (394 $\mathrm{mg}, 0.6 \mathrm{mmol})$ in $\mathrm{CH}_{2} \mathrm{Cl}_{2}(10 \mathrm{~mL})$ triflic acid $(65 \mu \mathrm{L}, 0.72 \mathrm{mmol})$ was added via microsyringe at $-40{ }^{\circ} \mathrm{C}$. The orange color of the solution became red-brown and IR spectrum show the transformation of $v_{\mathrm{CO}}$ bands of $\mathbf{3}\left(2030.0(\mathrm{~s}), 1980.0(\mathrm{~s}), 1900.5(\mathrm{~s}), 1827.0(\mathrm{~s}) \mathrm{cm}^{-1}\right)$ into those of the product [4](OTf) $\left(2044.0(\mathrm{~s}), 1996.0 \mathrm{~cm}^{-1}(\mathrm{~s})\right)$ and $\mathrm{CpMn}(\mathrm{CO})_{3}$ $\left(2022.5(\mathrm{~s}), 1935.0 \mathrm{~cm}^{-1}(\mathrm{vs})\right)$. The reaction mixture was stirred for 10 min at $-40{ }^{\circ} \mathrm{C}$ and then allowed to reach room temperature over $c a .15$ $20 \mathrm{~min}$. The resulting brown solution was loaded on a column of silica $(2 \times 10 \mathrm{~cm})$ and several yellow-brown bands containing $\mathrm{CpMn}(\mathrm{CO})_{3}$ and other unidentified impurities were eluted with pure $\mathrm{CH}_{2} \mathrm{Cl}_{2}$. The desired product [4](OTf) was then eluted with a $\mathrm{CH}_{2} \mathrm{Cl}_{2} / \mathrm{THF} 20: 1$ mixture as a yellow band. The eluate was evaporated under vacuum and the residue was dissolved in THF $(5 \mathrm{~mL})$. The solution was filtered through Celite, evaporated under vacuum and the product was thoroughly dried under vacuum to afford [4](OTf) $(337 \mathrm{mg}, 89 \%)$ as yellow powder. ${ }^{1} \mathrm{H} \mathrm{NMR}\left(400.1 \mathrm{MHz}, \mathrm{CDCl}_{3}, 25^{\circ} \mathrm{C}\right): \delta 8.36\left(\mathrm{~s}, 1 \mathrm{H}, \mathrm{CH}_{\mathrm{Im}-2}\right)$, 7.07 (s, 1H, CHIm-5), 7.04 (s, 2H, CH $H_{\text {Mes }}$ ), 6.99 (s, 2H, CH $H_{\text {Mes }}$ ), 5.09 (s, $5 \mathrm{H}, \mathrm{Cp}$ ), 2.35 (s, 3H, $\mathrm{CH}_{3}$-Mes), 2.32 (s, 3H, $\mathrm{CH}_{3}$-Mes), 2.08 (s, 6H, $\mathrm{CH}_{3}$ o-Mes $), 1.97$ (s, $6 \mathrm{H}, \mathrm{CH}_{3}$ o-Mes) $){ }^{13} \mathrm{C}\left\{{ }^{1} \mathrm{H}\right\} \mathrm{NMR}\left(100.6 \mathrm{MHz}, \mathrm{CDCl}_{3}\right.$, $\left.25^{\circ} \mathrm{C}\right): \delta 211.8(\mathrm{Fe}-\mathrm{CO}), 141.8\left(C_{\mathrm{Im}-4}-\mathrm{Fe}\right), 141.4,140.8\left(C-\mathrm{CH}_{3} p\right.$-Mes $)$, $138.2\left(\mathrm{CH}_{\mathrm{Im}-2}\right), 135.2,134.0\left(C-\mathrm{CH}_{3}\right.$ o-Mes $), 133.8\left(\mathrm{C}_{i-\mathrm{Mes}}\right), 132.2\left(\mathrm{CH}_{\mathrm{Im}-}\right.$ 5), $131.0\left(\mathrm{C}_{i \text {-Mes }}\right), 129.9,129.7\left(\mathrm{CH}_{\mathrm{Mes}}\right), 86.4(\mathrm{Cp}), 21.3,21.2\left(\mathrm{CH}_{3 p-}\right.$ Mes), 17.6, 17.3 ( $\mathrm{CH}_{3}$ o-Mes $)$. IR $\left(\mathrm{CH}_{2} \mathrm{Cl}_{2}\right)$ : v $v_{\mathrm{CO}} 2044.0$ (s), 1996.0 (s) $\mathrm{cm}^{-1}$. Elemental analysis calculated $(\%)$ for $\mathrm{C}_{29} \mathrm{H}_{29} \mathrm{~F}_{3} \mathrm{FeN}_{2} \mathrm{O}_{5} \mathrm{~S}: \mathrm{C}$, 55.25; H, 4.65; N, 4.45; found: C, 55.11; H, 4.65; N, 4.41.

Synthesis of complex [5](OTf). To a solution of [4](OTf) (126 mg, $0.2 \mathrm{mmol})$ and $\mathrm{Cp}(\mathrm{CO})_{2} \mathrm{FeI}(61 \mathrm{mg}, 0.2 \mathrm{mmol})$ in THF $(4 \mathrm{~mL}) \mathrm{a} \sim 1.7$ $\mathrm{M}$ solution of $t \mathrm{AmOK}$ in toluene $(175 \mu \mathrm{L}, 0.3 \mathrm{mmol})$ was added dropwise at $-80^{\circ} \mathrm{C}$. The reaction mixture was stirred at $-80^{\circ} \mathrm{C}$ for $30 \mathrm{~min}$ and then allowed to warm up to room temperature. IR spectrum showed the formation of [5](OTf) ( $v_{\mathrm{CO}} 2035.5$ (s), 2027.0 (sh), 1988.0 (s), $\left.1878.5(\mathrm{sh}) \mathrm{cm}^{-1}\right)$ as the main organometallic product. The volatiles were removed under vacuum and the residue was purified by chromatography on silica column $(1 \times 8 \mathrm{~cm})$. Several yellow-brown bands containing traces of $\mathrm{Cp}(\mathrm{CO})_{2} \mathrm{FeI}$ and other unidentified impurities were eluted with pure $\mathrm{CH}_{2} \mathrm{Cl}_{2}$. The product was then eluted with a $\mathrm{CH}_{2} \mathrm{Cl}_{2} / \mathrm{THF}$ 20:1 mixture as a yellow band. Evaporation of the solvent and drying the residue under vacuum afforded complex [5](OTf) (119 
mg, 74\%) as yellow powder. [5](OTf): ${ }^{1} \mathrm{H}$ NMR (400.1 $\mathrm{MHz}, \mathrm{CDCl}_{3}$, $25^{\circ} \mathrm{C}$ ): ${ }^{1} \mathrm{H}$ NMR $\left(400.1 \mathrm{MHz}, \mathrm{CDCl}_{3}, 25^{\circ} \mathrm{C}\right): \delta 7.07$ (s, $2 \mathrm{H}, \mathrm{CH}_{\mathrm{Mes}}$ ), 7.05 (s, 2H, CH $\left.H_{\mathrm{Mes}}\right), 6.79$ (s, 1H, CH $\left.H_{\mathrm{Im}-5}\right), 4.98$ (s, 5H, Cp-Fe), 4.79 (s, $5 \mathrm{H}, \mathrm{Cp}-\mathrm{Fe}$ ), 2.39 (s, 3H, $\mathrm{CH}_{3 p \text {-Mes }}$ ), 2.38 (s, 3H, $\mathrm{CH}_{3 p \text {-Mes }}$ ), 2.06 (s, 6H, $\mathrm{CH}_{3}$ o-Mes) 1.96 (s, $6 \mathrm{H}, \mathrm{CH}_{3}$ o-Mes) ${ }^{13} \mathrm{C}\left\{{ }^{1} \mathrm{H}\right\} \mathrm{NMR}\left(100.6 \mathrm{MHz}, \mathrm{CDCl}_{3}\right.$, $\left.25^{\circ} \mathrm{C}\right): \delta 212.7(\mathrm{Fe}-\mathrm{CO}), 210.3(\mathrm{Fe}-\mathrm{CO}), 166.7\left(\mathrm{Fe}-\mathrm{CN}_{2}\right), 140.6,140.3$ $\left(C-\mathrm{CH}_{3 p \text {-Mes }}\right), 139.9,137.9$ ( $\left.\mathrm{C}_{i \text {-Mes }}\right), 136.7,136.65\left(C-\mathrm{CH}_{3 o \text {-Mes }}\right), 136.6$ ( $\left.C_{\mathrm{Im}-4-\mathrm{Fe}}\right), 135.7\left(C_{\mathrm{Im}-5}\right), 130.1,129.8\left(C \mathrm{H}_{\mathrm{Mes}}\right), 86.2,86.1(\mathrm{Cp}-\mathrm{Fe})$, 21.35, $21.3\left(\mathrm{CH}_{3} p\right.$-Mes $), 18.9,18.4\left(\mathrm{CH}_{3}\right.$ o-Mes $)$. IR $\left(\mathrm{CH}_{2} \mathrm{Cl}_{2}\right)$ : v $v_{\mathrm{CO}} 2044.0$ (s), 2037.5 (s), 1998.0 (s), 1991.0 (sh) $\mathrm{cm}^{-1}$. HRMS (ESI) 657.1141 $\left(\mathrm{M}^{+}\right)$, calculated for $\mathrm{C}_{35} \mathrm{H}_{33} \mathrm{Fe}_{2} \mathrm{~N}_{2} \mathrm{O}_{4} 657.1139\left(\varepsilon_{\mathrm{r}}=0.3 \mathrm{ppm}\right)$.

Synthesis of complex [6](OTf). To a solution of $\left[\mathrm{Cp}(\mathrm{CO})_{2} \mathrm{Fe}\right.$ (IMes)]I ( $\left.177 \mathrm{mg}, 0.25 \mathrm{mmol}\right)$ in $\mathrm{CH}_{2} \mathrm{Cl}_{2}(5 \mathrm{~mL})$ a solution of NaOTf $(60 \mathrm{mg}, 0.35 \mathrm{mmol})$ in a nitrogen saturated water $(5 \mathrm{~mL})$ was added and the resulting biphasic mixture was vigorously shaken for 2 $\mathrm{min}$. Then the aqueous mixture was removed and the organic mixture was washed with water $(5 \mathrm{~mL})$, dried over $\mathrm{MgSO}_{4}$ and evaporated to dryness under vacuum. The residue was dissolved in THF $(5 \mathrm{~mL})$, filtered through Celite and evaporated to afford after drying under vacuum [6](OTf) (146 mg, 93\%) as yellow powder. ${ }^{1} \mathrm{H}$ NMR $(400.1 \mathrm{MHz}$, $\left.\mathrm{CDCl}_{3}, 25^{\circ} \mathrm{C}\right): \delta 7.37\left(\mathrm{~s}, 2 \mathrm{H}, \mathrm{CH}_{\mathrm{Im}-4,5)}, 7.08\right.$ (s, $\left.4 \mathrm{H}, \mathrm{C} H_{\mathrm{Mes}}\right), 4.82(\mathrm{~s}, 5 \mathrm{H}$, $\mathrm{Cp}), 2.38$ (s, 6H, $\mathrm{CH}_{3}$-Mes), 2.03 (s, 12H, CH $\left.\mathrm{o}_{\text {o-Mes }}\right) ;{ }^{13} \mathrm{C}\left\{{ }^{1} \mathrm{H}\right\} \mathrm{NMR}$ $\left(100.6 \mathrm{MHz}, \mathrm{CDCl}_{3}, 25^{\circ} \mathrm{C}\right): \delta 209.4(\mathrm{Fe}-\mathrm{CO}), 171.4\left(\mathrm{Fe}-\mathrm{CN}_{2}\right), 141.2$ $\left(C-\mathrm{CH}_{3} p\right.$-Mes $), 135.5$ ( $\left.\mathrm{C}_{i \text {-Mes }}\right), 135.4$ ( $C-\mathrm{CH}_{3}$ o-Mes $), 130.1$ ( $\left.C \mathrm{H}_{\text {Mes }}\right), 128.1$ $\left(C \mathrm{H}_{\mathrm{Im}-4,5)}\right), 86.1(\mathrm{Cp}), 21.3\left(\mathrm{CH}_{3}\right.$-Mes $), 18.1\left(\mathrm{CH}_{3}\right.$ o-Mes $)$. IR $\left(\mathrm{CH}_{2} \mathrm{Cl}_{2}\right)$ : $v_{\text {CO }} 2050.5(\mathrm{~s}), 2006.5 \mathrm{~cm}^{-1}$ (s) $\mathrm{cm}^{-1}$. Elemental analysis calculated (\%) for $\mathrm{C}_{29} \mathrm{H}_{29} \mathrm{~F}_{3} \mathrm{FeN}_{2} \mathrm{O}_{5} \mathrm{~S}$ : C, 55.25; H, 4.65; N, 4.45; found: C, 55.03; H, $4.41 ; \mathrm{N}, 4.34$

$\mathrm{X}$-ray diffraction experiment for complex 3. X-ray diffraction data were collected on a Bruker D8/APEX II/Incoatec Mo I $\mu$ S Microsource diffractometer using MoK $\alpha$ radiation $(\lambda=0.71073 \AA$, graphite monochromator). All calculations were performed on a PC compatible computer using the WinGX system. ${ }^{47}$ The structures were solved using the SIR92 program, ${ }^{48}$ which revealed in each instance the position of most of the non-hydrogen atoms. All the remaining non-hydrogen atoms were located by the usual combination of full matrix least-squares refinement and difference electron density syntheses using the SHELX program. ${ }^{49}$ Atomic scattering factors were taken from the usual tabulations. Anomalous dispersion terms for $\mathrm{Mn}$ and $\mathrm{Fe}$ atoms were included in Fc. All non-hydrogen atoms were allowed to vibrate anisotropically. The hydrogen atoms were set in idealized positions $\left(\mathrm{R}_{3} \mathrm{CH}, \mathrm{C}-\mathrm{H}=0.96\right.$ $\AA ; \mathrm{R}_{2} \mathrm{CH}_{2}, \mathrm{C}-\mathrm{H}=0.97 \AA \mathrm{RCH}_{3}, \mathrm{C}-\mathrm{H}=0.98 \AA$; $\mathrm{C}\left(\mathrm{sp}^{2}\right)-\mathrm{H}=0.93 \AA$; $\mathrm{U}_{\text {iso }} 1.2$ or 1.5 times greater than the $\mathrm{U}_{\text {eq }}$ of the carbon atom to which the hydrogen atom is attached) and their positions refined as "riding" atoms.

Computational details. Calculations were performed with the Gaussian $09^{50}$ package with the BP86 ${ }^{51}$ functional with D3 version of Grimme's dispersion $^{52}$ (DFT/BP86-D3) without any ligand simplification. For all atoms the Def2-TZVP ${ }^{53}$ basis set was applied. The structures of the all complexes were fully optimized on this level without any symmetry restrictions applying ultrafine integration grid and a tight SCF option. Vibrational frequencies were calculates at the same theory level and reported without applying any scaling factors.

Topological analysis of the electron-density distribution function $\rho(\mathrm{r})$ was performed using the $A I M A L L^{54}$ and Multiwfn v3. $6^{55}$ program packages based on the wave function obtained by the BP86 calculations. The energies of non-covalent interactions were calculated using the correlation between the binding energy $\left(\mathrm{E}_{\mathrm{BCP}}\right)$ and the value of the density-functional potential energy $\mathrm{V}_{\mathrm{C}}(\mathrm{r})$ in the corresponding critical point $(3,-1): \mathrm{E}=0.5 \cdot \mathrm{V}_{\mathrm{C}}(\mathrm{r}) \cdot{ }^{31}$ Bond ellipticity, $\varepsilon$ was defined as $\varepsilon=\left(\lambda_{1} / \lambda_{2}-1\right)$, where $\lambda_{1}$ and $\lambda_{2}$ are the negative eigenvalues of the Hessian of the electron density at the bond critical point ordered such that $\lambda_{1}<\lambda_{2}<0 .{ }^{30} \mathrm{NBO}$ analysis performed with the NBOPro 6.0 program. ${ }^{56}$

For bonding analysis all complexes were fully reoptimized with the ADF2014 ${ }^{57}$ program using BP86-D3 functional and TZP ${ }^{58}$ basis set. The overall geometry of complexes, as well as relative vibrational frequencies (Table S7) are similar to those of G09/BP86-D3/def2TZVP calculations. With the energy decomposition analysis (EDA) ${ }^{32}$ method, the fragments interaction energy, $\Delta \mathrm{E}_{\text {int }}$, was decomposed into terms $\Delta \mathrm{E}_{\text {int }}=\Delta \mathrm{E}_{\text {elst }}+\Delta \mathrm{E}_{\text {Pauli }}+\Delta \mathrm{E}_{\text {orb }}+\Delta \mathrm{E}_{\text {disp. }} . \Delta \mathrm{E}_{\text {orb }}$ was further decomposed with ETS-NOCV approach to the electron density transfer channels, $\Delta \rho_{\mathrm{i}}(\mathrm{r}) .^{38}$

Hydrosilylation of 2-acetonaphtone catalyzed by $\mathrm{Fe}$ (II) NHC complexes [4-6](OTf). A $10 \mathrm{~mL}$ oven-dried Schlenk tube containing a stirring bar, was charged with catalyst, 2 -acetonaphtone $(85.1 \mathrm{mg}, 0.5$ $\mathrm{mmol}), \mathrm{PhSiH}_{3}$ and toluene $(1 \mathrm{ml}, \mathrm{C}=0.5 \mathrm{M})$. The reaction mixture was placed in a pre-heated oil bath at $60^{\circ} \mathrm{C}$ and stirred for the indicated time. After cooling to room temperature $\mathrm{MeOH}(1 \mathrm{~mL})$ and $1 \mathrm{M}$ aqueous $\mathrm{NaOH}$ solution $(2 \mathrm{~mL})$ were added. The reaction mixture was vigorously stirred for 2 hours at room temperature and then extracted with $\mathrm{Et}_{2} \mathrm{O}(3 \times 10 \mathrm{ml})$. The combined organic layers were dried over $\mathrm{MgSO}_{4}$, filtered and evaporated under vacuum. The conversion was determined by ${ }^{1} \mathrm{H}$ NMR spectroscopy in the crude mixture by the ratio of proton signals at $\delta_{\mathrm{H}}$ of $8.47 \mathrm{ppm}$ of 2-acetonaphthone $\left(\mathrm{s}, 1 \mathrm{H}, \mathrm{CH}_{\mathrm{Ar}}\right)$ and $\delta_{\mathrm{H}}$ of $5.08 \mathrm{ppm}$ of $\alpha$-methyl-2-naphthylmethanol (q, $1 \mathrm{H}, \mathrm{CHCH}_{3}$ ). The isolation of the product was carried out by column chromatography on silica $(5 \times 1 \mathrm{~cm})$ using a 4:1 petroleum ether / EtOAc mixture to afford after drying under vacuum $\alpha$-methyl-2-naphthylmethanol (78 mg, 92\%).

\section{ASSOCIATED CONTENT}

\section{Supporting Information}

The Supporting Information is available free of charge on the ACS Publications website.

${ }^{1} \mathrm{H},{ }^{13} \mathrm{C}$ NMR spectra and cyclic voltammograms for all NHC complexes, additional DFT calculations data (PDF).

Cartesian coordinates for all G09 and ADF optimized structures (xyz).

\section{AUTHOR INFORMATION}

\section{Corresponding Authors}

* E-mail for N.L.: noel.lugan@1cc-toulouse.fr

* E-mail for V.C.: vincent.cesar@lcc-toulouse.fr

* E-mail for D.A.V.: dmitry.valyaev@1cc-toulouse.fr

ORCID

Oleg A. Filippov: 0000-0002-7963-2806

Yves Canac: 0000-0002-3747-554X

Jean-Baptiste Sortais: 0000-0003-1178-8588

Noël Lugan: 0000-0002-3744-5252

Vincent César: 0000-0002-6203-6434

Dmitry A. Valyaev: 0000-0002-1772-844X

Notes

The authors declare no competing financial interest.

\section{ACKNOWLEDGMENT}

We thank Centre National de la Recherche Scientifique (CNRS) and Institut Universitaire de France (IUF) for a general support of this project. A.A.G. is grateful to French Embassy in Moscow for a joint $\mathrm{PhD}$ fellowship (Vernadski program). Computational studies were performed using HPC resources from CALMIP (Grant no. P18038). O.A.F. thanks the Ministry of Science and Higher Education of the Russian Federation for partial support of this research.

\section{REFERENCES}

(1) Arduengo III, A. J.; Harlow, R. L.; Kline, M. A stable crystalline carbene. J. Am. Chem. Soc. 1991, 113, 361-363.

(2) Gründemann, S.; Kovacevic, A.; Albrecht, M.; Faller, J. W.; Crabtree, R. H. Abnormal binding in a carbene complex formed from an imidazolium salt and a metal hydride complex. Chem. Commun. 2001, 2274-2275.

(3) Aldeco-Perez, E.; Rosenthal, A. J.; Donnadieu, B.; Parameswaran, P.; Frenking, G.; Bertrand, G. Isolation of a C5-deprotonated imidazolium, a crystalline "abnormal" N-heterocyclic carbene. Science 2009, 326, 556-559. 
(4) (a) Sau, S. C.; Hota, P. K.; Mandal, S. K.; Soleilhavoup, M.; Bertrand, G. Stable abnormal N-heterocyclic carbenes and their applications. Chem. Soc. Rev. 2020, 49, 1233-1252; (b) Vivancos, A.; Segarra, C.; Albrecht, M. Mesoionic and related less heteroatom-stabilized Nheterocyclic carbene complexes: synthesis, catalysis, and other applications. Chem. Rev. 2018, 118, 9493-9586; (c) Crabtree, R. H. Abnormal, mesoionic and remote N-heterocyclic carbene complexes. Coord. Chem. Rev. 2013, 257, 755-766; (d) Schuster, O.; Yang, L.; Raubenheimer, H. G.; Albrecht, M. Beyond conventional N-heterocyclic carbenes: abnormal, remote, and other classes of NHC ligands with reduced heteroatom stabilization. Chem. Rev. 2009, 109, 3445-3478.

(5) Arnold, P. L.; Liddle, S. T. Deprotonation of N-heterocyclic carbenes to afford heterobimetallic organolanthanide complexes. Organometallics 2006, 25, 1485-1491.

(6) Wang, Y.; Xie, Y.; Abraham, M. Y.; Wei, P.; Schaefer, H. F.; Schleyer, P. v. R.; Robinson, G. H. A Viable Anionic N-Heterocyclic Dicarbene. J. Am. Chem. Soc. 2010, 132, 14370-14372.

(7) Ellul, C. E.; Mahon, M. F.; Saker, O.; Whittlesey, M. K. Abnormally bound $\mathrm{N}$-heterocyclic carbene complexes of ruthenium: $\mathrm{C}-\mathrm{H}$ activation of both $\mathrm{C} 4$ and $\mathrm{C} 5$ positions in the same ligand. Angew. Chem. Int. Ed. 2007, 46, 6343-6345.

(8) Rottschäfer, D.; Ebeler, F.; Strothmann, T.; Neumann, B.; Stammler, H.-G.; Mix, A.; Ghadwal, R. S. The viability of C5-protonated- and $\mathrm{C} 4, \mathrm{C} 5$-ditopic carbanionic abnormal NHCs: A new dimension in NHC chemistry. Chem. Eur. J. 2018, 24, 3716-3720.

(9) (a) Ghadwal, R. S. Carbon-based two electron $\sigma$-donor ligands beyond classical N-heterocyclic carbenes. Dalton Trans. 2016, 45 , 16081-16095; (b) Nasr, A.; Winkler, A.; Tamm, M. Anionic N-heterocyclic carbenes: Synthesis, coordination chemistry and applications in homogeneous catalysis. Coord. Chem. Rev. 2016, 316, 68-124; (c) Waters, J. B.; Goicoechea, J. M. Coordination chemistry of ditopic carbanionic N-heterocyclic carbenes. Coord. Chem. Rev. 2015, 293-294, $80-94$.

(10) Conversely, bimetallic transition metal complexes bearing the neutral isostructural 1,2,4-triazol-3,5-diylidene ligands have been reported, see: (a) Mata, J. A.; Hahn, F. E.; Peris, E. Heterometallic complexes, tandem catalysis and catalytic cooperativity. Chem. Sci. 2014, 5, 1723-1732; (b) Sabater, S.; Mata, J. A.; Peris, E. Hydrodefluorination of carbon-fluorine bonds by the synergistic action of a rutheniumpalladium catalyst. Nat. Commun. 2013, 4, 2553; (c) Zanardi, A.; Mata, J. A.; Peris, E. Well-defined Ir/Pd complexes with a triazolyl-diylidene bridge as catalysts for multiple tandem reactions. J. Am. Chem. Soc. 2009, 131, 14531-14537; (d) Guerret, O.; Solé, S.; Gornitzka, H.; Teichert, M.; Trinquier, G.; Bertrand, G. 1,2,4-Triazole-3,5-diylidene: A building block for organometallic polymer synthesis. J. Am. Chem. Soc. 1997, 119, 6668-6669.

(11) Wang, Y.; Xie, Y.; Abraham, M. Y.; Gilliard Jr., R. J.; Wei, P.; Campana, C. F.; Schaefer III, H. F.; von R. Schleyer, P.; Robinson, G. H. NHC-stabilized triorganozincates: syntheses, structures, and transformation to abnormal carbene-zinc complexes. Angew. Chem. Int. Ed. 2012, 51, 10173-10176.

(12) Armstrong, D. R.; Baillie, S. E.; Blair, V. L.; Chabloz, N. G.; Diez, J.; Garcia-Alvarez, J.; Kennedy, A. R.; Robertson, S. D.; Hevia, E. Alkali-metal-mediated zincation (AMMZn) meets N-heterocyclic carbene (NHC) chemistry: Zn-H exchange reactions and structural authentication of a dinuclear $\mathrm{Au}(\mathrm{I})$ complex with a NHC anion. Chem. Sci. 2013, 4, 4259-4266.

(13) (a) Simler, T.; Braunstein, P.; Danopoulos, A. A. Cobalt $\mathrm{PNC}^{\mathrm{NHC}}$ 'pincers': ligand dearomatisation, formation of dinuclear and $\mathrm{N}_{2}$ complexes and promotion of $\mathrm{C}-\mathrm{H}$ activation. Chem. Commun. 2016, 52, 2717-2720; b) Scheele, U. J.; Dechert, S.; Meyer, F. Noninnocence of $\mathrm{N}$-heterocyclic carbene ligands: intermolecular $\mathrm{C}-\mathrm{H}$ activation in allyl palladium NHC complexes. Chem. Eur. J. 2008, 14, $5112-5115$

(14) Krüger, A.; Kluser, E.; Müller-Bunz, H.; Neels, A.; Albrecht, M. Chelating C4-bound imidazolylidene complexes through oxidative addition of imidazolium salts to palladium(0). Eur. J. Inorg. Chem. 2012, 1394-1402.

(15) (a) Pardatscher, L.; Bitzer, M. J.; Jandl, C.; Kück, J. W.; Reich, R. M.; Kühn, F. E.; Baratta, W. Cationic abnormal N-heterocyclic carbene ruthenium complexes as suitable precursors for the synthesis of heterobimetallic compounds. Dalton Trans. 2018, 48, 79-89; (b) Bitzer, M. J.; Kühn, F. E.; Baratta, W. Tandem Suzuki-Miyaura/transfer hydrogenation reaction catalyzed by a $\mathrm{Pd}-\mathrm{Ru}$ complex bearing an anionic dicarbene. J. Catal. 2016, 338, 222-226; (c) Bitzer, M. J.; Pöthig, A.; Jandl, C.; Kühn, F. E.; Baratta, W. Ru-Ag and Ru-Au dicarbene complexes from an abnormal carbene ruthenium system. Dalton Trans. 2015, 44, 11686-11689.

(16) Valyaev, D. A.; Uvarova, M. A.; Grineva, A. A.; César, V.; Nefedov, S. N.; Lugan, N. Post-coordination backbone functionalization of an imidazol-2-ylidene and its application to synthesize heteropolymetallic complexes incorporating the ambidentate $\mathrm{IMesCO}_{2}^{-}$ligand. Dalton Trans. 2016, 45, 11953-11957.

(17) Grineva, A. A.; Filippov, O. A.; Nefedov, S. E.; Lugan, N.; César, V.; Valyaev, D. A. Direct Access to $\mathrm{IMes}^{\mathrm{F}}$ and $\mathrm{IMes}^{\mathrm{F}_{2}}$ by Electrophilic Fluorination of Abnormal N-Heterocyclic Carbenes. Organometallics 2019, 38, 2330-2337.

(18) Grineva, A. A.; Valyaev, D. A.; César, V.; Filippov, O. A.; Khrustalev, V. N.; Nefedov, S. E.; Lugan, N. Oxidative coupling of anionic abnormal N-heterocyclic carbenes: efficient access to Janustype 4,4'-bis(2H-imidazol-2-ylidene)s. Angew. Chem. Int. Ed. 2018, 57, 7986-7991.

(19) (a) Schowner, R.; Frey, W.; Buchmeiser, M. R. Understanding synthetic peculiarities of cationic molybdenum(VI) imido alkylidene $\mathrm{N}$-heterocyclic carbene complexes. Eur. J. Inorg. Chem. 2019, 1911-1922; (b) Petrov, P. A.; Sukhikh, T. S.; Sokolov, M. N. NHC adducts of tantalum amidohalides: the first example of NHC abnormally coordinated to an early transition metal. Dalton Trans. 2017, 46, 4902-4906; (c) Lebel, H.; Janes, M. K.; Charette, A. B.; Nolan, S. P. Structure and reactivity of "unusual" N-heterocyclic carbene (NHC) palladium complexes synthesized from imidazolium salts. J. Am. Chem. Soc. 2004, 126, 5046-5047.

(20) For related transition metal complexes bearing monodentate imidazol-4-ylidene ligands with other substituents at the nitrogen atoms, see: (a) Ghadwal, R. S.; Rottschäfer, D.; Andrada, D. M.; Frenking, G.; Schürmann, C. J.; Stammler, H.-G. Normal-to-abnormal rearrangement of an N-heterocyclic carbene with a silylene transition metal complex. Dalton Trans. 2017, 46, 7791-7799; (b) Koppaka, A.; Yempally, V.; Zhu, L.; Fortman, G. C.; Temprado, M.; Hoff, C. D.; Captain B. Synthesis of $\left[\mathrm{Pt}\left(\mathrm{SnBu}_{3}^{\mathrm{t}}\right)\left(\mathrm{IBu}^{\mathrm{t}}\right)(\mu-\mathrm{H})\right]_{2}$, a coordinatively unsaturated dinuclear compound which fragments upon addition of small molecules to form mononuclear $\mathrm{Pt}-\mathrm{Sn}$ complexes. Inorg. Chem. 2016, 55, 307-321; (c) Jin, H.; Tan, T. T. Y.; Hahn, F. E. Synthesis of complexes with abnormal "protic" N-heterocyclic carbenes. Angew. Chem. Int. Ed. 2015, 54, 13811-13815; (d) Jochmann, P.; Stephan, D. W. Zincocene and dizincocene $\mathrm{N}$-heterocyclic carbene complexes and catalytic hydrogenation of imines and ketones. Chem. Eur. J. 2014, 20, 8370-8378; (e) Day, B. M.; Pal, K.; Pugh, T.; Tuck, J.; Layfield, R. A. Carbene rearrangements in three-coordinate $\mathrm{N}$-heterocyclic carbene complexes of cobalt(II) bis(trimethylsilyl)amide. Inorg. Chem. 2014, 53, 10578-10584; (f) Pugh, T.; Layfield, R. A. Reactivity of three-coordinate iron-NHC complexes towards phenylselenol and lithium phenylselenide. Dalton Trans. 2014, 43, 4251-4254; (g) Day, B. M.; Pugh, T.; Hendriks, D.; Guerra, C. F.; Evans, D. J.; Bickelhaupt, F. M.; Layfield, R. A. Normal-to-abnormal rearrangement and NHC activation in three-coordinate iron(II) carbene complexes. J. Am. Chem. Soc. 2013, 135, 13338-13341; (h) Campeau, L.-C.; Thansandote, P.; Fagnou, K. High-yielding intramolecular direct arylation reactions with aryl chlorides. Org. Lett. 2005, 7, 1857-1860.

(21) Buchgraber, P.; Toupet, L.; Guerchais, V. Syntheses, properties, and X-ray crystal structures of piano-stool iron complexes bearing an N-heterocyclic carbene ligand. Organometallics 2003, 22, $5144-5147$

(22) (a) Johnson, C.; Albrecht, M. Piano-stool N-heterocyclic carbene iron complexes: Synthesis, reactivity and catalytic applications. Coord. Chem. Rev. 2017, 352, 1-14; (b) Bezier, D.; Sortais, J.-B.; Darcel, C. N-Heterocyclic carbene ligands and iron: an effective association for catalysis. Adv. Synth. Catal. 2013, 355, 19-33; c) Ingleson, M J.; Layfield, R. A. N-Heterocyclic carbene chemistry of iron: fundamentals and applications. Chem. Commun. 2012, 48, 3579-3589.

(23) (a) Bhunia, M.; Hota, P. K.; Vijaykumar, G.; Adhikari, D.; Mandal, S. K. A Highly efficient base-metal catalyst: chemoselective 
reduction of imines to amines using an abnormal-NHC-Fe(0) complex. Organometallics 2016, 35, 2930-2937; (b) Maddock, L. C. H.; Cadenbach, T.; Kennedy, A. R.; Borilovic, I.; Aromí, G.; Hevia, E. Accessing sodium ferrate complexes containing neutral and anionic N-heterocyclic carbene ligands: structural, synthetic, and magnetic insights. Inorg. Chem. 2015, 54, 9201-9210; (c) Musgrave, R. A.; Turbervill, R. S. P.; Irwin, M.; Herchel, R.; Goicoechea, J. M. Iron(II) complexes of ditopic carbanionic carbenes. Organometallics 2014, 43, 4335-4344; (d) Lavallo, V.; El-Batta, A.; Bertrand, G.; Grubbs, R. H. Insights into the carbene-initiated aggregation of $\left[\mathrm{Fe}(\mathrm{cot})_{2}\right]$. Angew. Chem. Int. Ed. 2011, 50, 268-271; (e) Danopoulos, A. A.; Tsoureas, N.; Wright, J. A.; Light, M. E. N-heterocyclic pincer dicarbene complexes of iron(II): C2 and C-5 metalated carbenes on the same metal center. Organometallics 2004, 23, 166-168.

(24) CCDC 2047741 contains full crystallographic information for complex 3. These data can be obtained free of charge from the Cambridge Crystallographic Data Centre via www.ccdc.cam.ac.uk/data_request/cif

(25) Johnson, C.; Abrecht, M. Triazolylidene iron(II) piano-stool complexes: synthesis and catalytic hydrosilylation of carbonyl compounds. Organometallics 2017, 36, 2902-2913.

(26) Caulton, K. G. Coordination chemistry of the manganese and rhenium fragments $\left(\mathrm{C}_{5} \mathrm{H}_{5}\right) \mathrm{M}(\mathrm{CO})_{2}$. Coord. Chem. Rev. 1981, 38, 1-43.

(27) (a) Elangovan, S.; Quintero-Duque, S.; Dorcet, V.; Roisnel, T.; Norel, L.; Darcel, C.; Sortais, J.-B. Knölker-type iron complexes bearing an N-heterocyclic carbene ligand: synthesis, characterization, and catalytic dehydration of primary amides. Organometallics 2015, 34 4521-4528; (b) César, V.; Misal Castro, L. C.; Dombray, T.; Sortais, J.-B.; Darcel, C.; Labat, S.; Miqueu, K.; Sotiropoulos, J.-M.; Brousses, R.; Lugan, N.; Lavigne, G. (Cyclopentadienyl)iron(II) complexes of Nheterocyclic carbenes bearing a malonate or imidate backbone: synthesis, structure, and catalytic potential in hydrosilylation. Organometallics 2013, 32, 4643-4655; (c) Valyaev, D. A.; Brousses, R.; Lugan, N.; Fernández, I.; Sierra, M. A. Do v(CO) stretching frequencies in metal carbonyl complexes unequivocally correlate with the intrinsic electron-donicity of ancillary ligands? Chem. Eur. J. 2011, 17, 6602-6605.

(28) Batool, M.; Martin, T. A.; Algarra, A. G.; George, M. W.; Macgregor, S. A.; Mahon, M. F.; Whittlesey, M. K. Photochemistry of $\mathrm{Cp}^{\prime} \mathrm{Mn}(\mathrm{CO})_{2}(\mathrm{NHC})\left(\mathrm{Cp}^{\prime}=\eta^{5}-\mathrm{C}_{5} \mathrm{H}_{4} \mathrm{Me}\right)$ species: synthesis, time-resolved IR spectroscopy, and DFT calculations. Organometallics 2012, 31, 4971-4979.

(29) (a) Bezier, D.; Jiang, F.; Roisnel, T.; Sortais, J.-B.; Darcel, C. Cyclopentadienyl-NHC iron complexes for solvent-free catalytic hydrosilylation of aldehydes and ketones. Eur. J. Inorg. Chem. 2012 1333-1337; (b) Das, P.; Elder, T.; Brennessel, W. W.; Chmely, S. C. Iron piano-stool complexes containing NHC ligands outfitted with pendent arms: synthesis, characterization, and screening for catalytic transfer hydrogenation. RSC Adv. 2016, 6, 88050-88056; (c) Prakasham, A P.; Gangwar, M. K.; Ghosh, P. $\beta$-Enaminone synthesis from 1,3-dicarbonyl compounds and aliphatic and aromatic amines catalyzed by iron complexes of fused bicyclic imidazo[1,5-a]pyridine derived N-heterocyclic carbenes. Eur. J. Inorg. Chem. 2019, 295-313.

(30) (a) Bader, R. F. W. Atoms in Molecules: A Quantum Theory, Oxford University Press, 1994; (b) Popelier, P. L. Atoms in Molecules: An Introduction; Prentice Hall; London; 2000; (c) Matta, C.; Boyd, R. J. Quantum Theory of Atoms in Molecules: Recent Progress in Theory and Application; Wiley-VCH: New York; 2007.

(31) (a) Espinosa, E.; Molins, E.; Lecomte, C. Hydrogen bond strengths revealed by topological analyses of experimentally observed electron densities. Chem. Phys. Lett. 1998, 285, 170-173; (b) Espinosa, E.; Alkorta, I.; Rozas, I.; Elguero, J.; Molins, E. About the evaluation of the local kinetic, potential and total energy densities in closed-shell interactions. Chem. Phys. Lett. 2001, 336, 457-461.

(32) (a) Ziegler, T.; Rauk, A. CO, CS, $\mathrm{N}_{2}, \mathrm{PF}_{3}$, and $\mathrm{MeNC}$ as $\sigma-$ donors and $\pi$-acceptors. A theoretical study by the Hartree-Fock-Slater transition-state method. Inorg. Chem. 1979, 18, 1755-1759; (b) Ziegler, T.; Rauk, A. A Theoretical study of the ethylene-metal bond in complexes between $\mathrm{Cu}^{+}, \mathrm{Ag}^{+}, \mathrm{Au}^{+}, \mathrm{Pt}^{0}$, or $\mathrm{Pt}^{2+}$ and ethylene, based on the Hartree-Fock-Slater transition-state method. Inorg. Chem. 1979, 18, 1558-1565; (c) Bickelhaupt, F. M.; Baerends E. J. Kohn-Sham density functional theory: predicting and understanding chemistry. In Rev. Comput. Chem.; Lipkowitz, K. B.; Boyd D. B. Eds.; John Wiley \& Sons, Inc.; 2007, pp. 1-86.

(33) (a) Pandey, K. K. Theoretical insights into the relative bonding of normal and abnormal $\mathrm{N}$-heterocyclic carbenes in $\left[\mathrm{PdCl}_{2}\left(\mathrm{NHC}^{\mathrm{R}}\right)_{2}\right]$ and $\left[\mathrm{PdCl}_{2}\left(\mathrm{NHC}^{\mathrm{R}}\right)\left(\mathrm{aNHC}^{\mathrm{R}}\right)\right](\mathrm{R}=\mathrm{H}, \mathrm{Ph}$, Mes). Int. J. Quantum Chem. 2016, 116, 537-546; (b) Xu, X.; Kim, S. H.; Zhang, X.; Das, A. K.; Hirao, H.; Hong, S. H. Abnormal N-heterocyclic carbene gold(I) complexes: synthesis, structure, and catalysis in hydration of alkynes. $\mathrm{Or}$ ganometallics 2013, 32, 164-171; (c) Tonner, R.; Heydenrych, G.; Frenking, G. Bonding analysis of N-heterocyclic carbene tautomers and phosphine ligands in transition-metal complexes: a theoretical study. Chem. Asian J. 2007, 2, 1555-1567.

(34) Kolychev, E. L.; Kronig, S.; Brandhorst, K.; Freytag, M.; Jones, P. G.; Tamm, M. Iridium(I) complexes with anionic N-heterocyclic carbene ligands as catalysts for the hydrogenation of alkenes in nonpolar media. J. Am. Chem. Soc. 2013, 135, 12448-12459.

(35) (a) Huynh, H. V. Electronic properties of N-heterocyclic carbenes and their experimental determination. Chem. Rev. 2018, 118, 9457-9492; (b) Dröge, T.; Glorius, F. The measure of all rings-N-heterocyclic carbenes. Angew. Chem. Int. Ed. 2010, 49, 6940-6952.

(36) Wolf, S.; Plenio, H. Synthesis of (NHC)Rh(cod)Cl and ( $\mathrm{NHC}) \mathrm{RhCl}(\mathrm{CO})_{2}$ complexes - translation of the Rh- into the Ir-scale for the electronic properties of NHC ligands. J. Organomet. Chem. 2009, 694, 1487-1492.

(37) For well-defined examples of ECE oxidation of $\mathrm{Ru}(\mathrm{II}) \mathrm{com}-$ plexes in acetonitrile involving 17/19-electron interconversion, see: (a) Hashidzume, K.; Tobita, H.; Ogino, H. Electrochemistry of octamethyl [3] ruthenocenophane: synthesis and structure of the first dicationic derivative of ruthenocene, $\left[\left\{\eta^{5}: \eta^{5}-\mathrm{C}_{5} \mathrm{Me}_{4}\left(\mathrm{CH}_{2}\right)_{3} \mathrm{C}_{5} \mathrm{Me}_{4}\right\} \mathrm{Ru}(\mathrm{NCMe})\right]-$ $\left(\mathrm{PF}_{6}\right)_{2}$. Organometallics 1995, 14, 1187-1194; (b) Noss, M. E.; Hylden, A. T.; Carroll, P. J.; Berry, D. H. Electrochemistry of ruthenium bis(imino)pyridine compounds: evidence for an ECE mechanism and isolation of mono and dicationic complexes. Inorg. Chem. 2018 , $57,435-445$.

(38) Mitoraj, M.; Michalak, A.; Ziegler, T. A Combined charge and energy decomposition scheme for bond analysis. J. Chem. Theory Comput. 2009, 5, 962-975.

(39) Fraser, R.; van Rooyen, P. H.; de Lange, J.; Cukrowski, I.; Landman, M. Synthesis, structure and DFT study of asymmetrical NHC complexes of cymantrene derivatives and their application in the dehydrogenative dimerization reaction of thiols. J. Organomet. Chem. 2017, 840, 11-22.

(40) (a) Couzijn, E. P. A.; Lai, Y.-Y.; Limacher, A.; Chen, P. Intuitive quantifiers of charge flows in coordinate bonding. Organometallics 2017, 36, 3205-3214; (b) Bernhammer, J. C.; Frison, G.; Huynh, $\mathrm{H}$. V. Electronic structure trends in N-heterocyclic carbenes (NHCs) with varying number of nitrogen Atoms and NHC-transition-metal bond properties. Chem. Eur. J. 2013, 19, 12892-12905.

(41) (a) Liang, Q.; Song, D. Iron N-heterocyclic carbene complexes in homogeneous catalysis. Chem. Soc. Rev. 2020, 49, 1209-1232; (b) Wei, D.; Darcel, C. Iron catalysis in reduction and hydrometalation reactions. Chem. Rev. 2019, 119, 2550-2610.

(42) For the comparison of catalytic performance between transition metal complexes bearing structurally close normal and abnormal NHCs, see refs. 33b and 42a,b. (a) Byun, S.; Park, S.; Choi, Y.; Ryu, J. Y.; Lee, J.; Choi, J.-H.; Hong, S. Highly efficient ethenolysis and propenolysis of methyl oleate catalyzed by abnormal N-heterocyclic carbene ruthenium complexes in combination with a phosphine-copper cocatalyst. ACS Catal. 2020, 10, 10592-10601; (b) Xu, X.; Xu, B.; Li, Y.; Hong, S. H. Abnormal N-heterocyclic carbene promoted Suzuki-Miyaura coupling reaction: a comparative study. Organometallics 2010, 29, 6343-6349.

(43) For the evaluation of catalytic activity of abnormal and ditopic $\mathrm{Ru}(\mathrm{II})$ complexes in transfer hydrogenation of ketones, see references $15 a-b$.

(44) Yasuda, S.; Yorimitsu, H.; Oshima, K. Synthesis of aryliron complexes by palladium-catalyzed transmetalation between $\left[\mathrm{CpFe}(\mathrm{CO})_{2} \mathrm{I}\right]$ and aryl Grignard reagents and their chemistry directed toward organic synthesis. Organometallics 2008, 27, 4025-4027. 
(45) Fulmer, G. R.; Miller, A. J. M.; Sherden, N. H.; Gottlieb, H. E.; Nudelman, A.; Stoltz, B. M.; Bercaw, J. E.; Goldberg, K. I. NMR chemical shifts of trace impurities: common laboratory solvents, organics, and gases in deuterated solvents relevant to the organometallic chemist. Organometallics 2010, 29, 2176-2179.

(46) Connelly, N. G.; Geiger, W. E. Chemical redox agents for organometallic chemistry. Chem. Rev. 1996, 96, 877-910.

(47) Farrugia, L. J. WinGX and ORTEP for Windows: an update. $J$. Appl. Crystallogr. 2012, 45, 849-854.

(48) Altomare, A.; Cascarano, G.; Giacovazzo, C.; Guagliardi, A. SIR92 - a program for automatic solution of crystal structures by direct methods. J. Appl. Crystallogr. 1994, 27, 435-436.

(49) Sheldrick, G. M. A short history of SHELX. Acta Crystallogr., Sect. A: Found. Crystallogr. 2008, 64, 112.

(50) Frisch, M. J.; Trucks, G. W.; Schlegel, H. B.; Scuseria, G. E.; Rob, M. A.; Cheeseman, J. R.; Jr, J.A.M.; Vreven, T.; Kudin, K. N.; Burant, J. C.; Millam, J. M.; Iyengar, S. S.; Tomasi, J.; Barone, V.; Mennucci, B.; Cossi, M.; Scalmani, G.; Rega, N.; Petersson, G. A.; Nakatsuji, H.; Hada, M.; Ehara, M.; Toyota, K.; Fukuda, R.; Hasegawa, J.; Ishida, M.; Nakajima, T.; Honda, Y.; Kitao, O.; Nakai, H.; Klene, M.; Li, X.; Knox, J. E.; Hratchian, H. P.; Cross, J. B.; Bakken, V.; Adamo, C.; Jaramillo, J.; Gomperts, R.; Stratmann, R. E.; Yazyev, O.; Austin, A. J.; Cammi, R.; Pomelli, C.; Ochterski, J. W.; Ayala, P. Y.; Morokuma, K.; Voth, G. A.; Salvador, P.; Dannenberg, J. J.; Zakrzewski, V. G.; Dapprich, S.; Daniels, A. D.; Strain, M. C.; Farkas, O.; Malick, D. K.; Rabuck, A. D.; Raghavachari, K.; Foresman, J. B.; Ortiz, J. V.; Cui, Q.; Baboul, A. G.; Clifford, S.; Cioslowski, J.; Stefanov, B. B.; Liu, G.; Liashenko, A.; Piskorz, P.; Komaromi, I.; Martin, R. L.; Fox, D. J.; Keith, T.; Al-Laham, M. A.; Peng, C. Y.; Nanayakkara, A.; Challacombe, M.; Gill, P. M. W.; Johnson, B.; Chen, W.; Wong, M. W.; Gonzalez, C.; Pople, J. A. Gaussian 09, Revision D.01, Gaussian, Inc., Wallingford, CT, 2009.

(51) (a) Becke, A. D. Density-functional exchange-energy approximation with correct asymptotic behavior. Phys. Rev. A 1988, 38, 3098-3100; (b) Perdew, J. P. Density-functional approximation for the correlation energy of the inhomogeneous electron gas. Phys. Rev. B 1986, 33, 8822-8824.
(52) Grimme, S.; Antony, J.; Ehrlich, S.; Krieg, H. A consistent and accurate $a b$ initio parametrization of density functional dispersion correction (DFT-D) for the 94 elements H-Pu. J. Chem. Phys. 2010, 132, 154104.

(53) (a) Weigend, F.; Ahlrichs, R. Balanced basis sets of split valence, triple zeta valence and quadruple zeta valence quality for $\mathrm{H}$ to Rn: Design and assessment of accuracy. Phys. Chem. Chem. Phys. 2005, 7, 3297-3305; (b) Weigend, F. Accurate Coulomb-fitting basis sets for H to Rn. Phys. Chem. Chem. Phys. 2006, 8, 1057-1065.

(54) AIMAll (Version 19.10.12), T. A. Keith, TK Gristmill Software, Overland Park KS, USA, 2019 (aim.tkgristmill.com).

(55) Lu, T.; Chen, F. Multiwfn: a multifunctional wavefunction analyzer. J. Comput. Chem. 2012, 33, 580-592.

(56) NBO 6.0. Glendening, E. D.; Badenhoop, J. K.; Reed, A. E.; Carpenter, J. E.; Bohmann, J. A.; Morales, C. M.; Landis, C. R.; Weinhold, F. Theoretical Chemistry Institute, University of Wisconsin, Madison, 2013.

(57) Baerends, E. J.; Ziegler, T.; Autschbach, J.; Bashford, D.; Bérces, A.; Bickelhaupt, F. M.; Bo, C.; Boerrigter, P. M.; Cavallo, L.; Chong, D. P.; Deng, L.; Dickson, R. M.; Ellis, D. E.; van Faassen, M.; Fan, L.; Fischer, T. H.; Fonseca Guerra, C.; Ghysels, A.; Giammona, A.; van Gisbergen, S. J. A.; Götz, A. W.; Groeneveld, J. A.; Gritsenko, O. V.; Grüning, M.; Gusarov, S.; Harris, F. E.; van den Hoek, P.; Jacob, C. R.; Jacobsen, H.; Jensen, L.; Kaminski, J. W.; van Kessel, G.; Kootstra, F.; Kovalenko, A.; Krykunov, M. V.; van Lenthe, E.; McCormack, D. A.; Michalak, A.; Mitoraj, M.; Neugebauer, J.; Nicu, V. P.; Noodleman, L.; Osinga, V. P.; Patchkovskii, S.; Philipsen, P. H. T.; Post, D.; Pye, C. C.; Ravenek, W.; Rodríguez, J. I.; Ros, P.; Schipper, P. R. T.; Schreckenbach, G.; Seldenthuis, J. S.; Seth, M.; Snijders, J. G.; Solà, M.; Swart, M.; Swerhone, D.; te Velde, G.; Vernooijs, P.; Versluis, L.; Visscher, L.; Visser, O.; Wang, F.; Wesolowski, T. A.; van Wezenbeek, E. M.; Wiesenekker, G.; Wolff, S. K.; Woo, T. K.; Yakovlev, A. L. ADF2014, SCM, Theoretical Chemistry, Vrije Universiteit.

(58) Van Lenthe, E.; Baerends, E. J. Optimized Slater-type basis sets for the elements 1-118. J. Comput. Chem. 2003, 24, 1142-1156. 


\section{Table of Contents artwork and text}

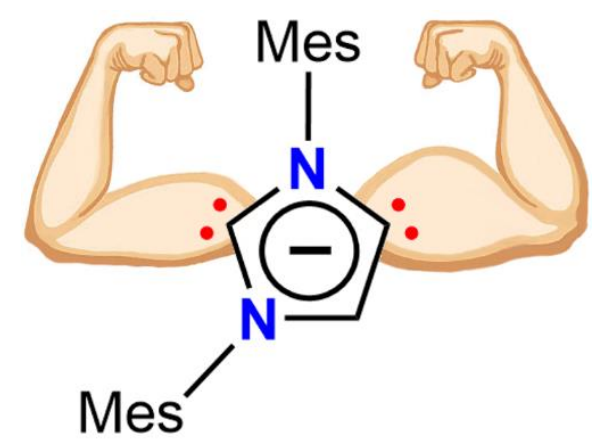

Superior electronic donation of imidazol-2,4-diylidene ligand vs. the monocarbenic ligands was quantified by IR spectroscopy and cyclic voltammetry on the corresponding mono- and bimetallic Mn(I) and $\mathrm{Fe}(\mathrm{II})$ complexes. The observed effect was rationalized by DFT calculations in terms of a synergy between increased $\sigma$-donation and decreased $\pi$-backdonation of both normal and abnormal carbene fragments being especially pronounced in the latter case. 